\title{
Minimalism and Optimality Theory
}

Hans Broekhuis and Ellen Woolford

(To appear in the Cambridge Handbook of Generative Syntax)

Final version: December 9, 2010

\section{Introduction}

This chapter discusses the relation between the minimalist program (MP) and optimality theory (OT) and will show that, contrary to popular belief, MP and OT are not inherently incompatible or competing frameworks/theories. Instead, we will show (i) that the two can well be seen as complementary parts of a more general model of grammar and (ii) that the resulting hybrid system may be superior to the two constituting parts in isolation. Before we discuss the hybrid system, we provide background on some characteristic features of MP and OT in Section 2. Section 3 shows that the hybrid system makes it possible to eliminate the EPP-features from MP by replacing them by an OT-evaluation of the output of the computational system. Although this need not necessarily be seen as a step forwards, we will show that it provides us with a theory of Scandinavian object shift that is far superior to the proposal in Chomsky (2001) and which raises a number of new and interesting questions concerning Holmberg's Generalization; cf. Holmberg (1986/1999). Section 4 goes a step further by showing that the replacement of certain inviolable conditions on the operation Agree from MP by an OT-evaluation of the output of the computational system solves a set of intricate questions concerning Burzio's Generalization and cross-linguistic variation in the case-licensing of nominative objects. ${ }^{1}$

\section{Some Characteristic Features of the Minimalist Program and Optimality Theory}

Before we discuss the hybrid system it is necessary to briefly lay out the properties of MP and OT. The focus here will be on OT, given that MP is more extensively discussed in various other chapters of this volume. An important conclusion will be that, contrary to what the name suggests, OT-syntax resembles MP in that it is not a theory but a program in the sense that it implies neither a specific theory of the generative component nor of the evaluative module that evaluates the output of the system; it is a theory of constraint interaction that computes the predictions for any generator and set of postulated constraints. We will furthermore argue that the overall modeling of the syntactic module presupposed by MP is very similar to that proposed by OT-syntax. This will make it possible to develop a new program that incorporates certain basic assumptions and guiding intuitions from both MP and OT. Section 3 and 4 will illustrate two implementations of the hybrid program.

\subsection{The Minimalist Program}

Given that minimalism is not a theory but a program, which refers to a family of approaches that aim at reducing syntax/grammar to its absolute minimum, we will simply pick out one of the more familiar approaches for illustration, viz., the one developed by Chomsky (1995) and, especially, subsequent work. The overall structure of the model that has arisen since Chomsky (2000) is given in Figure 1. Below, we will briefly summarize some of the

\footnotetext{
${ }^{1}$ The two authors of this chapter are no exception to the general rule that no two researchers agree on every assumption. The main goal of the discussions in Sections 3 and 4 is to illustrate the logical properties of the hybrid system: The specific proposals described here are based on earlier work of the two authors of this chapter. Taken together they do not constitute a single, consistent theory in all respects, but we did not attempt to resolve the tensions between the two proposals here; leaving this as a matter for future research.
} 
properties of this model that will be central to our concern. Various other aspects of Chomsky's recent work (like phase theory) will not be discussed here; see Chapter XX for a more complete discussion.

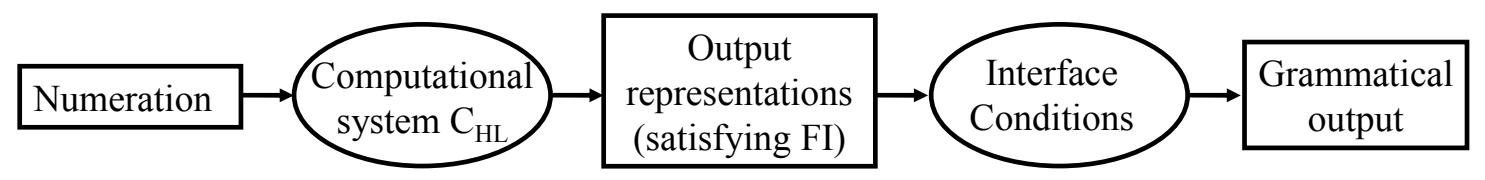

\section{Figure 1: Minimalist Program}

The derivation takes a numeration as its input, the elements of which are processed by the operations of the computational system for human language $\mathrm{C}_{\mathrm{HL}}$. The first operation is EXTERNAL MERGE (henceforth: Merge), which combines elements from the numeration and/or larger syntactic objects already formed into larger structures. The merged elements may contain unvalued formal features that must be valued by entering into the syntactic relation AGREE with some other element in their syntactic (c-command) domain with corresponding valued formal features: the unvalued features thus function as probes that search within a certain domain for a goal with corresponding valued features. ${ }^{2}$ It is further assumed that this probe can be assigned a so-called EPP-FEATURE, which requires that the goal be placed in its minimal domain (in the sense of Chomsky 1995: ch.3) by means of INTERNAL MERGE (henceforth: Move). When the numeration is exhausted, the subsequent applications of Merge and Move must have resulted in an output representation that satisfies Full Interpretation, that is, which only consists of elements that can be given an interpretation by either the Conceptual-Intentional (C-I) or the Articulatory-Perceptual (A-P) system; if not, the derivation crashes at these interfaces. The operations of $\mathrm{C}_{\mathrm{HL}}$ are subject to LAST RESORT in the sense that they may only apply when forced: Merge must apply given that the derivation must result in a single syntactic object, which implies that the numeration must be exhausted at the end of the derivation; Agree is forced by Full Interpretation given that unvalued formal features cannot be interpreted by the C-I or A-P system. Move, finally, is forced by the need to eliminate the EPP-features: it is often assumed that these features must be eliminated immediately after they are introduced in the structure in order for the derivation to be able to proceed (see Chapter YY).

The computational system $\mathrm{C}_{\mathrm{HL}}$ is seen as invariant among languages and defines a set of possible output representations for each numeration. The fact that languages vary in word order (that is, give rise to different output representations on the basis of similar numerations) is accounted for by assuming that languages may be parameterized with respect to the question whether a certain probe, like the unvalued formal feature(s) on the functional heads of the clause (including the light verb $v^{*}$ ), is associated with an EPP-feature. ${ }^{3}$ In earlier minimalist work, it was assumed that the option of having or not having an EPP-feature was fixed once and for all in the lexicon of the language in question, but Chomsky (2001) suggested that the EPP-features can (at least sometimes) be optionally assigned to a certain

\footnotetext{
${ }^{2}$ With respect to case features, the views of the two authors diverge: Broekhuis adopts the view that the case feature on $\mathrm{T}$ and the verb are initially unvalued, while Woolford assumes that they are valued; see the discussion in Section 4.2.

${ }^{3}$ Section 3 will show that the unvalued formal feature(s) on $v^{*}$ ( $=$ the light verb that creates a transitive verb from the verbal root $\mathrm{V}$ ) are the ones that trigger object shift (when an EPP-feature is present). The nature of these feature(s) depends on the version of MP one adopts: until recently, it was assumed that the light verb $v^{*}$ has accusative case features, but Chomsky (2008) has proposed that the relevant features are $\varphi$-features and that case is simply a reflex of agreement. Section 3 and 4 will adopt the more traditional view; we refer the reader to Broekhuis (2005) for a critical assessment of the empirical motivation underlying Chomsky's more recent claim.
} 
probe, which may account for certain "optional" movements like object shift in Icelandic. However, given that object shift is sensitive to the information structure of the clause, Chomsky claims that (at least in this case) the assignment of an EPP-feature is subject to an effect-on-output condition: an EPP-feature can only be assigned when this has repercussions for the meaning of the clause. We will return to this in Section 3.

The effect-on-output condition, which in effect functions as a filter on the set of possible output representations, is an example of a larger set of so-called interface conditions (as were the global economy, bare output, interface, etc. conditions postulated in earlier and other versions of MP). Although these conditions are assumed to play an important role in selecting the grammatical output representations for a certain language $\mathrm{L}$, it seems that the minimalist community has failed so far to develop a general format that such conditions must meet. The aim of this chapter is to show that OT may fill that gap.

\subsection{Optimality Theory}

This section will briefly discuss what we will refer to as traditional OT-syntax. ${ }^{4}$ Section 2.2 .1 will start with presenting the basic ideas shared by researchers working within OT, which will subsequently be illustrated for syntax in Section 2.2.2. Section 2.2.3 will conclude this brief discussion of OT-syntax by showing that OT-syntax is not a theory, but instead resembles MP in that it functions as a research program.

\subsubsection{Shared basic ideas}

Just like MP, OT-syntax is not a theory but a program. It refers to a family of approaches that adopt the model of grammar in Figure 2. The guiding intuition of OT is that the language system consists of two components, viz., a generative device called GENERATOR that produces candidate sets and a language-specific filtering device called EVALUATOR that selects candidates from these candidate sets as optimal (= well-formed) in a given language L.

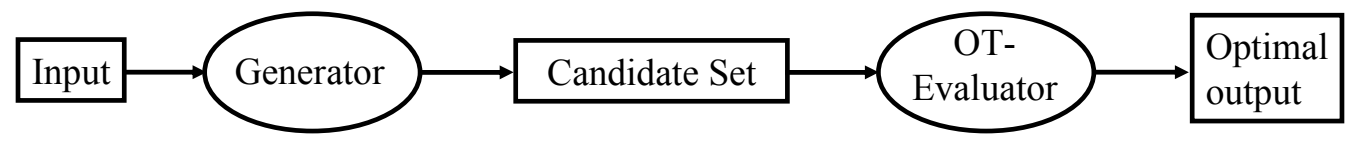

\section{Figure 2: Optimality Theory}

Furthermore, OT adopts the basic assumption that the evaluator consists of a universal set of VIOLABLE CONSTRAINTS (usually referred to as CON) and that it is the LANGUAGE-SPECIFIC RANKING of these constraints that determines which candidates from the candidate sets are optimal in L. The determination of the optimal candidate thus proceeds as in (1), which we have adapted from Archangeli (1997).

(1) The evaluator finds the candidate that best satisfies the ranked constraints, such that:

a. violation of a lower ranked constraint is tolerated if this enables the candidate to satisfy a higher ranked constraint, and

b. ties by violation or by satisfaction of a higher ranked constraint are resolved by a lower ranked constraint.

\subsubsection{An illustration}

The way the OT-evaluator works can readily be demonstrated by means of Pesetsky's $(1997 ; 1998)$ analysis of the pronunciation patterns of relative clauses. Pesetsky adopts the standard assumption that relative clauses are derived by means of $w h$-movement of (the

\footnotetext{
${ }^{4}$ There are alternative versions of OT like Harmonic Grammar (Legendre et al 1990), Stochastic OT (Boersma 1998), and Bidirectional OT (2000), which diverge in various ways from the form OT discussed here, but we will not discuss these approaches here.
} 
phrase containing) the relative pronoun, followed by optional deletion of the phonological content of the relative pronoun and/or the complementizer. His aim is to provide an OTalternative for Chomsky \& Lasnik (1977) proposal that the pronunciation patterns in (2) arise as the result of the DOUBLY FILLED COMP FILTER and the RECOVERABILITY CONDITION on deletion.
a. the man $\left[\mathrm{who}_{\mathrm{i}}\right.$ I know $\left.t_{\mathrm{i}}\right]$
b. the man [ that I know $t_{\mathrm{i}}$ ]
c. the man [ $\left[\right.$ know $t_{\mathrm{i}}$ ]
d. *the man $\left[\right.$ who $_{\mathrm{i}}$ that I know $\left.t_{\mathrm{i}}\right]$

$\mathrm{a}^{\prime}$. the book [[pp about which $]_{\mathrm{i}}$ he spoke $\left.t_{\mathrm{i}}\right]$

$\mathrm{b}^{\prime}$. *the book [[pP $]_{\mathrm{i}}$ that he spoke $\left.t_{\mathrm{i}}\right]$

$\mathrm{c}^{\prime}$. *the book [[pp he spoke $\left.t_{\mathrm{i}}\right]$

$\mathrm{d}^{\prime} . *$ the book $\left[[\mathrm{pP} \text { about which }]_{\mathrm{i}}\right.$ that he spoke $\left.t_{\mathrm{i}}\right]$

Pesetsky's proposal also aims at accounting for the fact that the pronunciation pattern is language-specific. The contrast between the primeless examples in (2) and (3) shows that English allows a wider range of pronunciation patterns with a bare relative pronoun than French. However, when the relative pronoun is embedded in a larger constituent, like the PPs in the primed examples, the two languages behave the same.
a. *l'homme [qui je connais $t_{\mathrm{i}}$ ]
$a^{\prime} . \quad$ l'homme [[pp avec qui $]_{\mathrm{i}}$ j'ai dansé $\left.t_{\mathrm{i}}\right]$
b. l'homme [qui que je connais $t_{\mathrm{i}}$ ]
$\mathrm{b}^{\prime}$. *l'homme [[pp qui] $]_{\mathrm{i}}$ que j'ai dansé $\left.t_{\mathrm{i}}\right]^{\prime}$

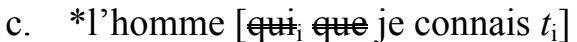
$\mathrm{c}^{\prime}$. *1'homme $\left[\text { pp qui }_{\mathrm{i}} \text { j'ai dansé } t_{\mathrm{i}}\right]_{3}$
d. *l'homme [qui $i_{i}$ que je connais $t_{\mathrm{i}}$ ]
$\mathrm{d}^{\prime}$. *l'homme [[pp avec qui $]_{\mathrm{i}}$ que j'ai dansé $\left.t_{\mathrm{i}}\right]$

Pesetsky accounts for the data in (2) and (3) by means of the universal constraints in (4), which we have slightly simplified here for reasons of exposition: (4a) is simply Chomsky \& Lasnik's (1977) recoverability condition on deletion, (4b) is a constraint that favors embedded clauses introduced by a complementizer, and (4c) is a constraint that favors the deletion of function words (like complementizers).

(4) a. RECOVERABILITY (REC): a syntactic unit with semantic content must be pronounced unless it has a sufficiently local antecedent.

b. LEFT EDGE (CP): the first leftmost pronounced word in an embedded CP must be the complementizer.

c. TELEGRAPH (TEL): do not pronounce function words.

The analysis crucially relies on the fact that LE(CP) in (4b) and TEL in (4c) are in conflict: the former favors complementizers to be pronounced, whereas the latter favors them to be deleted. This makes it possible to account for variation between languages by varying the ranking of these constraints: when LE(CP) outranks TEL, as in (5a), we get a language in which embedded declarative clauses must be introduced by a complementizer; when TEL outranks $\mathrm{LE}(\mathrm{CP})$, as in (5b), we get a language in which embedded declarative clauses are not introduced by a complementizer; and when we assume that the two constraints are in a tie, as in (5c), we get a language in which embedded declarative clauses are optionally introduced by a complementizer.

(5) a. $\quad \mathrm{LE}(\mathrm{CP})>>$ TEL: embedded declarative clauses are introduced by a complementizer.

b. TEL $>>$ LE $(C P)$ : embedded declarative clauses are not introduced by a complementizer.

c. $\quad \mathrm{TEL}<>\mathrm{LE}(\mathrm{CP})$ : embedded declarative clauses are optionally introduced by a complementizer.

It is important to realize that a tie like (5c) expresses that the rankings in (5a) and (5b) are simultaneously active in the language in question; the set of optimal candidates selected by $(5 c)$ is the union of the sets of optimal candidates selected by (5a) and (5b); see Müller (1999) 
for a discussion of various uses of the notion of tie. The evaluations can be made visible by means of tableaux. Tableau 1 gives the evaluation of embedded declarative clauses with and without a pronounced complementizer in a language with the ranking in (5a). The two asterisks indicate that the constraint in the header of their column is violated by the candidate in question. The (a)-candidate, with a pronounced complementizer, violates TEL but this is tolerated because it enables us to satisfy the higher ranked constraint LE(CP); cf. (1a). The (b)candidate, with a deleted complementizer, violates LE(CP), and this is fatal, which is indicated by an exclamation mark, because the (a)-candidate does not violate this constraint. The (a)candidate is therefore optimal, which is indicated by means of the pointed finger: The shading of cells following the fatal constraint violation indicates that these cells do not play a role in the evaluation; this convention is mainly for convenience, because it makes larger tableaux easier to read.

Tableau 1: No C-deletion in embedded declarative clauses

\begin{tabular}{|c|c|c|}
\hline & LE(CP) & 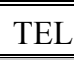 \\
\hline a. $\sigma^{2 . . .}[$ complementizer ....] & & $*$ \\
\hline$\ldots . .[$ emplementiza. ....] & $* !$ & \\
\hline
\end{tabular}

Now consider the evaluation of the same candidates in a language with the ranking in $(5 b)$, given in Tableau 2. Since TEL is now ranked higher than LE(CP), violation of the former is fatal, so that deletion of the complementizer becomes obligatory.

Tableau 2: Obligatory $C$-deletion in embedded declarative clauses

\begin{tabular}{||l||c|c||}
\hline & TEL & LE(CP) \\
\hline \hline a. $\quad \ldots .[$ complementizer ....] & $* !$ & \\
\hline b. $\ldots[$. & & $*$ \\
\hline
\end{tabular}

Tableau 3 gives the evaluation according to the ranking in $(5 \mathrm{c})$, where the two constraints are in a tie, which is indicated in the tableau by means of a dashed line. Under this ranking the two rankings in $(5 \mathrm{a} \& \mathrm{~b})$ are simultaneously active. Therefore we have to read the tie in both directions: when we read the tie from left to right, the violation of LE(CP) is fatal (which is indicated by ${ }^{*}>$ ), and the (a)-candidate is optimal; when we read the tableau from right to left, the violation of TEL is fatal (which is indicated by $*<$ ), and the (b)-candidate is optimal. This predicts that deletion of the complementizer is optional in this case, since a candidate is only excluded by tied constraints when there is a fatal violation in both directions; cf. the discussion of Tableau 5.

Tableau 3: Optional C-deletion in embedded declarative clauses

\begin{tabular}{||l||c:c||}
\hline & LE(CP) & TEL \\
\hline \hline a. ${ }^{*} \ldots[$ complementizer ....] & & $*<$ \\
\hline b. ${ }^{\circ} \ldots[$....] & $*>$ & \\
\hline
\end{tabular}

Note in passing that the ranking in $(5 \mathrm{c})$ accounts for the fact that the two constructions are both possible but has nothing to say about their relative frequency. This is not surprising given that we are dealing here with core syntax/competence; the relative frequency of the two constructions should rather be accounted for by some performance theory (which may be given shape as some version of stochastic OT, mentioned in footnote 4). 
Let us now return to the difference between English and French with respect to the pronunciation patterns of relative clauses. It is clear that English is a language of type (5c) given that the complementizer is normally optional in embedded declarative clauses. French, on the other hand, is a language of type (5a): the complementizer is obligatory in embedded declarative clauses. Pesetsky has shown that this also accounts for the differences between the primeless English and French examples of (2) and (3), in which a bare relative pronoun is preposed, provided that we assume that in both languages the constraint RECOVERABILITY outranks the constraints TEL and LE(CP).

$$
\begin{aligned}
& \text { a. French: } \mathrm{REC}>>\mathrm{LE}(\mathrm{CP})>>\text { TEL } \\
& \text { b. English: } \mathrm{REC}>>\mathrm{TEL}<>\mathrm{LE}(\mathrm{CP})
\end{aligned}
$$

Tableau 4 provides the evaluation of the primeless French examples in (3). Since the relative pronoun has a local antecedent it is recoverable after deletion, so that all candidates satisfy REC. The (b)-candidate is the optimal candidate because it is the only one that does not violate $\mathrm{LE}(\mathrm{CP})$; the fact that this candidate violates the lower-ranked constraint TEL is tolerated since this enables the satisfaction of the higher-ranked constraint LE(CP); cf. (1a).

\begin{tabular}{|c|c|c|c|c|}
\hline Fren & & REC & LE(CP) & TEL \\
\hline & l'homme [qui $i_{i}$ je connais $t_{\mathrm{i}}$ ] & & $* !$ & \\
\hline b. & l'homme [ ${ }_{i}$ que je connais $t_{\mathrm{i}}$ ] & & & $*$ \\
\hline c. & l'homme [uili je connais $t_{\mathrm{i}}$ ] & & $* !$ & \\
\hline $\mathrm{d}$. & l'homme [qui ${ }_{\mathrm{i}}$ que je connais $t_{\mathrm{i}}$ ] & & $* !$ & $*$ \\
\hline
\end{tabular}

\section{Tableau 4: Relative clauses with preposed relative pronoun}

The evaluation of the corresponding English examples is given in Tableau 5, which is slightly more complex due to the fact that $\mathrm{LE}(\mathrm{CP})$ and TEL are in a tie. We are therefore dealing with two rankings at the same time: REC $>$ LE(CP) $>$ TEL and REC $>$ TEL $>>$ LE(CP). The first ranking is the one we also find in French, and we have seen that this results in selection of the (b)-candidate as optimal. Under the second ranking, violation of TEL is fatal, so that the (a)and the (c)-candidate are selected as optimal. As a result, three out of the four candidates are acceptable in English.

\begin{tabular}{|c|c|c|c|}
\hline English & REC & LE(CP) & TEL \\
\hline a. the man $\left[w^{2} o_{\mathrm{i}} \mathrm{I}\right.$ know $\left.t_{\mathrm{i}}\right]$ & & $*>$ & \\
\hline b. the man [ $\left[\theta_{\mathrm{i}}\right.$ that I know $t_{\mathrm{i}}$ ] & & & $*<$ \\
\hline c. $\rightarrow$ the man [ $\left[\right.$ know $\left.t_{\mathrm{i}}\right]$ & & $*>$ & \\
\hline the man $\left[w_{h o}\right.$ that I know $t_{\mathrm{i}}$ ] & & $*>$ & $*<$ \\
\hline
\end{tabular}

Tableau 5: Relative clauses with preposed relative pronoun

Next consider the evaluation of the French examples in Tableau 6, in which a PP containing a relative pronoun is preposed. Since the preposition is not locally recoverable, deletion of it leads to a violation of the highest-ranked constraint REC: this excludes the (b)- and the (c)-candidate. Since the two remaining candidates both violate LE(CP), the lowest ranked constraint TEL gets the final say by excluding the (d)-candidate; cf. (1b). Note that this shows that the subranking LE(CP) $>>$ TEL does not mean that the complementizer is always realized, but that this depends on the question whether it is preceded by some other element that must be realized; if so, TEL forces the complementizer to delete. 
Tableau 6: Relative clauses with preposed PP

\begin{tabular}{|c|c|c|c|c|}
\hline Fren & & REC & $\overline{\mathrm{LE}(\mathrm{CP})}$ & 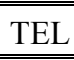 \\
\hline a. & l'homme [[avec qui] $]_{\mathrm{i}}$ j'ai dansé $\left.t_{\mathrm{i}}\right]$ & & * & \\
\hline b. & l'homme $\left[[]_{\mathrm{i}}\right.$ que j'ai dansé $\left.t_{\mathrm{i}}\right]$ & $* !$ & & * \\
\hline c. & l'homme [[ j'ai dansé $\left.t_{\mathrm{i}}\right]$ & $* !$ & $*$ & \\
\hline d. & l'homme [[avec quil $]_{\mathrm{i}}$ que j'ai dansé $\left.t_{\mathrm{i}}\right]$ & & $*$ & $* !$ \\
\hline
\end{tabular}

Tableau 7 shows that we get the same result for the corresponding English examples: both the (b)- and the (c)-candidate are excluded by REC, and the (d)-candidate is excluded because it is harmonically bound by the (a)-candidate, that is, it has a fatal violation of TEL irrespective of whether we read the tie from left to right or from right to left. We will simply indicate violations of tied constraints that are fatal on all rankings available in the language by means of an exclamation mark.

Tableau 7: Relative clauses with preposed PP

\begin{tabular}{|ll|c|c|c||}
\hline English & REC & LE(CP) & TEL \\
\hline \hline a. & the book [[about which $]_{\mathrm{i}}$ & & \\
\hline b. $\quad$ the book $\left[\left[\right.\right.$ he spoke $\left.t_{\mathrm{i}}\right]$ & & $*$ & \\
\hline c. $\quad$ the book $\left[[]_{\mathrm{i}}\right.$ that he spoke $\left.t_{\mathrm{i}}\right]$ & $* !$ & & $*$ \\
\hline d. $\quad$ the book [[about which $]_{\mathrm{i}}$ that he spoke $\left.t_{\mathrm{i}}\right]$ & & $*$ & $* !$ \\
\hline
\end{tabular}

\subsubsection{OT-syntax is a meta-theory or program, not a theory}

Although OT-syntacticians agree that the language system consists of a generator that produces candidate sets and an evaluator that selects candidates from these sets as optimal in a given language L by means of the procedure in (1), they may have widely varying ideas on the nature of the generator and, as a result, the constraints that constitute the evaluator. The generator can take the form of virtually any imaginable generative device, as is clear from the fact that the current OT-approaches to syntax are based on very different and often incompatible linguistic theories. Some more or less random examples are given in (7).

\footnotetext{
a. Lexical-Functional Grammar: Bresnan (2000); Sells (2001)

b. Early Principles-and-Parameters Theory: Grimshaw (1997); Pesetsky (1998)

c. Minimalism: Dekkers (1999); Broekhuis \& Dekkers (2000); Heck \& Müller (2000); Woolford (2007); Broekhuis (2008)

d. Others: Müller (2000/2001); Vogel (2006a)
}

Since the generators postulated by the proposals in (7) differ considerably and the generated candidate sets will therefore be constituted by candidates with entirely different properties, the postulated constraints will be quite different as well. This can be illustrated by comparing the OT-approaches proposed in Grimshaw (1997), Broekhuis (2008), and Dekkers (1999), which are all based on some version of the principles-and-parameters theory. Grimshaw's (1997) proposal was originally written in the early 90's and is based on the pre-minimalist principles-and-parameters framework. Among other things, this is clear from the fact that she tries to capture the directionality parameter, which was still generally adopted at that time, by means of two conflicting constraints HEAD LEFT and HEAD RIGHT (the head is leftmost/rightmost in its projection). In addition, she assumes the alignment constraints SPECIFIER LEFT and SPECIFIER RIGHT (the specifier is leftmost/rightmost in its projection). Given that Grimshaw also assumes that the structures created by the generator conform to the 
general X-bar-schema, the linearization of these structures follows from the language-specific ranking of these four constraints. Broekhuis (2008), which is based on the minimalist machinery proposed in Chomsky (2000) and later work, need not make use of Grimshaw's alignment constraints given that he adopts some form of the universal base hypothesis, according to which linear order is derived from the hierarchical relations between the constituents in the output representation (as expressed by Kayne's, 1994, Linear Correspondence Axiom). In his approach, linear order therefore follows from the languagespecific ranking of a set of the so-called EPP-constraints, which favor movement of a goal into its probe's minimal domain, and the economy constraint *MOVE, which disfavors movement. For example, the "strong" ranking EPP(case) $>{ }^{*}$ MOVE requires movement of the probed noun phrase into the minimal domain of the unvalued case features of the verb or the inflectional node I, whereas the "weak" ranking *MOVE $>$ EPP(case) requires that the probe remain in its original position; see Section 3 for details. This proposal, which expresses the same intuition as Chomsky's Agree-based approach that Agree is normally sufficient for convergence, will find no place in OT-approaches that follow Groat \& O'Neil (1996) in assuming that feature checking invariably triggers movement and that the linear order depends on the question whether it is the tail or the head of the resulting chain that is spelled out; such approaches will replace the EPP-constraints by, e.g., Dekkers' (1999) PARSE-F constraints, which favor pronunciation of moved constituents in the position of their formal feature (the head of the chain), and reinterpret *MOVE as a constraint that favors pronunciation of moved elements in their base position (the tail of the chain). This brief discussion demonstrates that properties of the proposed generator are immediately reflected in the nature of the postulated violable constraints of the OT-evaluator. The differences between the three OT-approaches discussed here are relatively small due to the fact that the proposed generators all find their origin in the Chomskyan generative tradition, but it will be clear that the differences between these OT-approaches and OT-approaches that are based on other traditions may be much larger. Note that the choice of the correct generator and the selection of the correct set universal constraints are, of course, both empirical issues.

\subsection{Combining the Minimalist Program and Optimality Theory}

When we compare Figure 1 and Figure 2, we see immediately that the overall structure of Chomsky's version of MP has much in common with the model assumed in standard OT. Both have a generative device that defines a set of possible structures, from which languages select a subset of acceptable sentences by means of some filtering device. From the discussion in the preceding sections, it will have become clear that the two devices are not equally well developed in the two programs. Minimalist research has focused mainly on the generative device, despite the fact that the following quote from Chomsky (1995:220) shows that a filtering device was postulated right from the start:

"The language $\mathrm{L}$ thus generates three relevant sets of derivations: the set $\mathrm{D}$ of derivations, a subset $\mathrm{D}_{\mathrm{C}}$ of convergent derivations of $\mathrm{D}$, and a subset $\mathrm{D}_{\mathrm{A}}$ of admissible derivations of $\mathrm{D}$. [Full Interpretation] determines $\mathrm{D}_{\mathrm{C}}$, and the economy conditions select $\mathrm{D}_{\mathrm{A}} \cdot[\ldots] \mathrm{D}_{\mathrm{A}}$ is a subset of $\mathrm{D}_{\mathrm{C}}$.

Although the filtering device has been endowed with various names in the respective stages of the minimalist framework (they have been referred to as global economy, bare output, interface and effect-on-output conditions), relatively little work has been devoted to developing a coherent theory of it. The situation in OT is rather the reverse: much work has been devoted to the substantive content of the filtering device (that is, the constraints and their ranking), but virtually no attention has been paid to the generator. Given this situation it 
might be useful to combine the two approaches by assuming that the generative device is some version of the computational system $\mathrm{C}_{\mathrm{HL}}$, and that the filtering device is some version of the OT-evaluator, as in Figure 3.

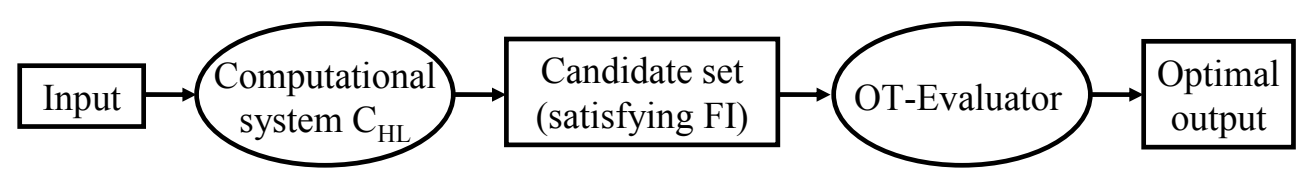

\section{Figure 3: The architecture of grammar}

A potential advantage of this hybrid MP + OT model is that it provides OT-syntax with an explicitly formulated generator and MP with at least a general format for expressing the interface conditions. Furthermore, now that both devices have been assigned an explicit format, we can seriously investigate the division of labor between the two components. For example, Broekhuis and Dekkers (2000) have noted that Pesetsky's RECOVERABILITY is rather suspect as an OT-constraint given that it is never violated: it is always the highest ranked constraint. This suggests that we are actually dealing with an inviolable condition on the operation Delete, which must therefore be added to the inventory of syntactic operations in $\mathrm{C}_{\mathrm{HL}}$. Given that the derivation is cyclic, the postulation of Delete makes it impossible to account for the recoverability restriction by appealing to the availability of some local antecedent. Therefore, the restriction must rather be formulated in terms of semantic features, which will have various ramifications for the analysis of the pronunciation patterns of relative clauses. We will not digress here on this specific issue any further, but refer the reader to Dekkers (1999) for further discussion.

An important point is that the hybrid model may substantially change our views on the properties ascribed to the generative and filtering device by traditional MP/OT. Our hope is that we can simplify current MP by expressing all language-specific statements (including the more recent effect-on-output conditions discussed above) by means of language-specific rankings of otherwise universal violable constraints. For example, MP stipulates that languages differ with respect to question of whether functional heads force movement of the phrases with which they are in an Agree-relation. A formal way of expressing this is by assuming that such heads may or may not have an epp-feature. The following section will show that it is not only readily possible to replace the notion of epp-feature by a small set of violable constraints, but that doing this also results in a descriptively more adequate theory.

\section{Eliminating the EPP-features}

This section, which is based on Broekhuis (2000;2008), will discuss certain aspects of Scandinavian object shift (henceforth: OS). Section 3.1 will start with discussing Chomsky's (2001) syntactic account of OS in order to further underpin our claim that current MP employs language-specific output filters. Section 3.2 will propose an OT-version of Chomsky's filter and show that the postulated constraints can also be readily used to express the macro-parameterizations concerning OS. Section 3.3 will argue that the OS data unambiguously show that, contrary to what has been claimed in some minimalist approaches, verb movement must be considered an instantiation of syntactic movement, and provide an OT-account of some differences between the Germanic languages in this respect; it will also show that the proposed OT-accounts of OS and verb movement interact in interesting ways. 


\subsection{Chomsky's (2001) Account of Icelandic Object Shift.}

Earlier versions of MP assumed that the option of having or not having an EPP-feature was fixed in the lexicon of the language in question, but it soon became clear that this could not be maintained. Chomsky (2001) adopts the configuration in (8), where Object $_{\theta}$ is the thematic position of the object and Object $_{s}$ is an outer specifier position of $v^{*}$ created by OS triggered by the case feature on the light verb $v^{*}$ (cf. Vikner 1994; 2006), provided at least that $v^{*}$ is also associated with an EPP-feature.

$$
\ldots\left[{ }_{\alpha} \text { Object }_{\mathrm{s}}\left[\text { Subject } v^{*}\left[\mathrm{~V} \ldots \text { Object }_{\theta}\right]\right]\right]
$$

If we assume that the lexicon determines once and for all whether $v^{*}$ is assigned an EPPfeature or not, we expect languages to behave rigidly with respect to OS by categorically forcing or blocking it. This runs afoul, however, with the examples in (9), which show that Icelandic OS depends on the information structure of the clause: OS is only possible when the object is part of the presupposition of the clause; cf. Holmberg (1999). From this, we may conclude that OS is at least partly externally motivated, and that we have to introduce additional means to account for the data in (9). ${ }^{5}$

$$
\begin{aligned}
& \text { a. Jón keypti ekki bókina. } \\
& \text { Jón bought not the book } \\
& \text { b. Jón keypti bókina }{ }_{i} \text { ekki } t_{\text {bókina }}
\end{aligned}
$$

bókina $\subset$ focus

bókina $\subset$ presupposition

More evidence against assuming that the lexicon fully determines whether $v^{*}$ is assigned an EPP-feature or not is provided by the examples in (10), which show that OS is also sensitive to its syntactic environment: in complex verb constructions like (10), OS is excluded irrespective of the information structure of the clause, and (10a) is therefore ambiguous.

$$
\begin{aligned}
& \text { a. Jón hefur ekki keypt bókina. } \\
& \text { Jón has not bought the book } \\
& \text { b. *Jón hefur bókina ekki keypt } t_{\text {bokina }}
\end{aligned}
$$

bókina $\subset$ focus or presupposition

One way to rescue the earlier proposal that the lexicon determines once and for all whether $v^{*}$ is assigned an EPP-feature is to follow Holmberg (1999), who claims that OS is actually not part of core grammar but a phonological operation that is driven by the interpretation of the object. This is formulated more precisely in (11a), which paraphrases Chomsky's (2001:31) summary of Holmberg's proposal. Holmberg (1999:15) accounts for the ungrammaticality of (10b) by postulating the additional restriction on the application of OS in (11b): OS is blocked in (10b) because it would move the object across the main verb.

\footnotetext{
${ }^{5}$ Chomsky (2001) does not address the question of why OS must cross the sentential adverbs: if these adverbs are $v^{*} \mathrm{P}$-external and the object moves into the outer specifier of $v^{*} \mathrm{P}$, this would not be expected. Broekhuis (2008) solves this problem by assuming that OS involves the creation of an extended projection (in the sense of Grimshaw 1997) of $v^{*}$ : if Merge of the adverb applies before OS, the desired crossing will be obtained, as is shown by (ia). Note that it is not necessary to stipulate rule ordering given that the alternative order (OS before Merge of adverb) will result in a surface string in which OS has applied string vacuously, as is shown by (ib). This derivation can be excluded by means of a surface constraint (which originates from Chomsky 1986) that disfavors string vacuous movement. Since we do not have the space to digress on this, we refer the reader to Broekhuis (2008) for detailed discussion.
}
a. $\quad\left[\operatorname{Subj} \mathrm{I}+\mathrm{V}+\mathrm{v}\left[\mathrm{Obj} \mathrm{v}\left[\mathrm{Adv}\left[t_{\mathrm{Subj}} t_{\mathrm{v}}\left[t_{\mathrm{V}} t_{\mathrm{Obj}}\right]\right]\right]\right]\right]$
b. $\quad\left[\right.$ Subj I $\left.+\mathrm{V}+\mathrm{V}\left[\mathrm{Adv}\left[\mathrm{Obj} \mathrm{v}\left[t_{\mathrm{Subj}} t_{\mathrm{V}}\left[t_{\mathrm{V}} t_{\mathrm{Obj}}\right]\right]\right]\right]\right]$ 
(11) a. Object shift is a phonological movement that satisfies condition (11b) and is driven by the semantic interpretation INT of the shifted object:

(i) INT: object is part of the presupposition of the clause.

(ii) $\mathrm{INT}^{\prime}$ : object is part of the focus of the clause.

b. Holmberg's Generalization (1999 version): Object shift cannot apply across a phonologically visible category asymmetrically c-commanding the object position except adjuncts.

Chomsky (2001:32) correctly argues that Holmberg's proposal is problematic because "displacement rules interspersed in the phonological component should have little semantic effect" (p.15), and he therefore maintains that OS takes place in core syntax. ${ }^{6}$

Chomsky's (2001: ex. (61)) own solution to the problem concerning the "optionality" of OS is given in (12), where INT and INT' are different interpretations defined as in (11a), and we will see below that this boils down to filtering out the unwanted form-meaning pairs by means of a language-specific output filter.

(12) a. $\quad v^{*}$ is assigned an EPP-feature only if that has an effect on outcome.

b. The EPP position of $v^{*}$ is assigned INT.

c. At the phonological border of $v^{*} \mathrm{P}, \mathrm{XP}$ is assigned $\mathrm{INT}^{\prime}$.

Chomsky suggests that (12a) is an invariant principle of grammar; it intends to express that $v^{*}$ is only assigned an EPP-feature when the resulting movement affects the semantic interpretation of the output representation, or when it makes $\mathrm{A}^{\prime}$-movement possible by placing the object at the phonological edge of the $v^{*} \mathrm{P}$-phase. Clause (12b) is likewise claimed to be an invariant principle: an object occupying the position Object $_{s}$ in (8) in the output representation must be construed as being part of the presupposition of the clause. It is important to note that $(12 \mathrm{~b})$ is silent on non-shifted objects, which correctly predicts that nonshifted objects in Icelandic examples like (10a) or in non-OS languages like English can be interpreted as part of either the focus or the presupposition of the clause.

Given that (12b) does not restrict the interpretation of non-shifted objects, we need something in addition to account for the fact that OS is obligatory in examples like (9b). This is where (12c) comes in, which intends to express that the object will be interpreted as being part of the focus of the clause when it is $v^{*} \mathrm{P}$-internally and not c-commanded by $v^{*} \mathrm{P}$-internal phonological material.

(13) $\mathrm{XP}$ is at the phonological border of $v^{*} \mathrm{P}$, iff:

a. $\quad \mathrm{XP}$ is a $v^{*} \mathrm{P}$-internal position; and

b. $\quad \mathrm{XP}$ is not c-commanded by $v^{*} \mathrm{P}$-internal phonological material.

The main difference between the examples in (9) and (10) is that in the former the main verb has moved out of $v^{*} \mathrm{P}$ into $\mathrm{T}$, whereas in the latter it has not and thus occupies a $v^{*} \mathrm{P}$-internal position. Example (10a) is therefore correctly predicted to be ambiguous: since the $v^{*+\mathrm{V}}$ complex is $v^{*} \mathrm{P}$-internal and c-commands the object, clause (12c) does not apply and the object can therefore be interpreted either as part of the focus of the clause (INT') or as part of the presupposition of the clause (INT). Example (10b) is consequently blocked by (12a) because OS has no effect on the outcome as the object can also be assigned the interpretation INT in its base position in (10a). Therefore, in constructions like (10), the EPP-feature can only be assigned to $v^{*}$ if it is needed to enable $\mathrm{A}^{\prime}$-movement. In (9), on the other hand, there

\footnotetext{
${ }^{6}$ There are a number of additional problems with Holmberg's (1999) proposal, which are extensively discussed in Broekhuis (2008: section 4.3.3). For example, (11b) is assumed to constrain both syntactic and phonological movement, and phonological movement thus simply seems to introduce an additional syntactic cycle, which is only needed to circumvent certain problems for strict cyclicity.
} 
is no $v^{*} \mathrm{P}$-internal phonological material that c-commands the $\theta$-position of the object. Consequently, if the object occupies this position, (12c) states that it must be assigned INT'. OS therefore has an effect on the outcome because it enables the assignment of INT, so that (12a) allows assignment of an EPP-feature to $v^{*}$.

It is important to note that statement (12c) clearly functions as a filter in the sense of Chomsky \& Lasnik (1977). First, it is clear that it cannot be considered an intrinsic condition on the operation Move; when we apply (12c) to the intermediate stage in (8), the desired distinction between (9) and (10) cannot be made yet, because the verb and the subject are moved out of the $v^{*} \mathrm{P}$ only at a later stage in the derivation. Chomsky (2001) therefore assumes that (12c) applies to the resulting representation at the higher phase level (CP). Secondly, (12c) is a language-specific statement: Icelandic is subject to it, and therefore OS is forced in examples like (9b); Danish, on the other hand, is not subject to it, so that (12a) blocks OS in Danish examples like (14).

(14) a. Hvorfor læste studenterne ikke artiklen?

why read the students not the article

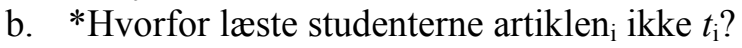

Chomsky (2001:36) presents clause (12c) as a parameter that distinguishes OS from non-OS languages, which correctly distinguishes between languages like Icelandic, which do, and Finnish-Swedish, which do not have OS. It seems, however, that (12c) is unlike the parameters of the earlier principles-and-parameters framework in that it is not binary. This is clear from the fact that a language like Danish has limited OS: it is like Finnish-Swedish in not allowing OS of non-pronominal DPs, but like Icelandic in that OS of weak pronouns is possible; see the contrast between (14) and (15).

(15) a. Hvorfor læste studenterne den $n_{\mathrm{i}}$ ikke $t_{\mathrm{i}}$ ?

why read the students it not

b. *Hvorfor læste studenterne ikke den?

This can be accounted for by refining clause (12c) as in $\left(12 c^{\prime}\right)$. This clause makes the following correct predictions: (i) non-pronominal DPs that are part of the presupposition of the clause (= INT) must undergo OS in Icelandic, but not in Finnish-Swedish or Danish; (ii) definite pronouns (which are assigned INT by definition) must undergo OS in Icelandic and Danish; (iii) Finnish-Swedish does not have any kind of OS because the set of elements that is assigned $\mathrm{INT}^{\prime}$ in the relevant context is empty, which is indicated by " $\varnothing$ ".

$\mathrm{c}^{\prime}$. At the phonological border of $v^{*} \mathrm{P}, \mathrm{XP}$ is assigned INT
(i) $\mathrm{XP}=\mathrm{DP}$
(ii) $\mathrm{XP}=$ weak definite pronoun
(Icelandic)
(iii) $\mathrm{XP}=\varnothing$
(Danish)
(Finnish-Swedish)

The discussion above has shown that Chomsky's proposal regulates OS by means of language-specific filters on the output representation. In fact, this proposal raises the question whether we still need the EPP-features. Given that the output filters decide whether a certain

\footnotetext{
${ }^{7}$ Chomsky's proposal crucially presupposes that reordering of phonological material does not satisfy (12a); if it did, object shift would be allowed in (10b) given that it inverts the order of the main verb and the object. Restricting the effect-on-output condition to semantics is surprising, however, given that in Chomsky's (1995:294) earlier work this notion explicitly referred to properties of PF; see in this connection also Chomsky's (1986: section 9) Vacuous Movement Hypothesis and Williams' (2003:162) suggestion that linearization and interpretation play a similar role in making movement "visible".
} 
movement is licit or not, we may just as well assume that movements that satisfy the Last Resort Condition apply optionally; the unwanted structures can then be filtered out by appealing to the effect-on-output condition in tandem with the language-specific filter in $\left(12 c^{\prime}\right)$. This would enable us to attribute cross-linguistic language variation entirely to the evaluator, just as in OT. In (16), we rephrase Chomsky's proposal such that reference to the notion of EPP-feature indeed becomes superfluous.

(16) a. Move is possible only if it has an effect on outcome.

b. The derived object position is assigned INT.

c. At the phonological border of $v^{*} \mathrm{P}, \mathrm{XP}$ is assigned INT'
(i) $\mathrm{XP}=\mathrm{DP}$
(ii) $\mathrm{XP}=$ weak definite pronoun
(Icelandic)
(iii) $\mathrm{XP}=\varnothing$
(Danish)
(Finnish-Swedish)

\subsection{An OT-account of Object Shift}

Eliminating the EPP-features is of course highly desirable from a minimalist perspective as it furthers the goal of reducing the computational system to its absolute minimum by eliminating the parameterization introduced by these features: it makes $\mathrm{C}_{\mathrm{HL}}$ into a truly universal system that mechanically applies to a given input. However, given that elimination of the EPP-features shifts the explanatory burden entirely to the interface conditions, it will be clear that it is unsatisfying to appeal to more or less randomly formulated and languagespecific output filters of the sort in (16); a more general theory of these filters is called for, and OT can provide the format for such a theory. Elimination of the EPP-features is also advantageous from an OT-perspective given that the resulting version of $\mathrm{C}_{\mathrm{HL}}$ fully satisfies McCarthy \& Prince's (1993) description of the OT-generator as consisting of linguistic operations subject to "very general considerations of structural well-formedness"; $\mathrm{C}_{\mathrm{HL}}$ simply consists of general operations like Agree and Merge without any built-in language-specific properties.

We will assume that the resulting hybrid MP + OT system must meet certain minimalist demands of design, which implies among other things that the set of constraints be small and that the formulation of the individual constraints be simple (see Broekhuis 2008 for detailed discussion). The constraints proposed here build on previous work in that they all have some correlate in the principles-and-parameters tradition (and, more specifically, in current MP). We start with formulating an OT-counterpart of the EPP-features from traditional MP by postulating a family of violable EPP-constraints, which generalizes the GB-style EPP (SpecIP must be filled) by requiring that all probes (unvalued formal features) trigger movement of their goal into their specifier.

(17) $\operatorname{EPP}(\mathrm{F})$ : probe $\mathrm{F}$ attracts its goal.

a. $\quad \operatorname{EPP}($ case): an unvalued case feature attracts its goal.

b. $\operatorname{EPP}(\varphi)$ : unvalued $\varphi$-features attract their goal.

c. etc.

The EPP-constraints in (17) interact in an OT-fashion with the economy constraint *MOVE, which prohibits movement. As a result, claiming that *MOVE outranks EPP(case) is more or less equivalent to saying that no EPP-feature is assigned to probes with an unvalued case feature, whereas claiming that EPP(case) outranks *MOVE is more or less equivalent to saying that these probes are assigned an EPP-feature. The two rankings in (18a\&b) thus express a macro-parameterization between OS and non-OS languages. In order to facilitate discussion, we will adapt the weak/strong terminology from Chomsky (1995) and henceforth refer to these rankings as, respectively, the WEAK and STRONG RANKING of EPP(case). 
(18) a. Weak ranking: *MOVE $>>\operatorname{EPP}($ case $) \Rightarrow$ case features normally do not trigger OS

b. Strong ranking: $\mathrm{EPP}($ case $)>*^{*} \mathrm{MOVE} \Rightarrow$ case features normally trigger OS

An important advantage of this OT-formalization of the "strength" property is that it follows without further ado that we can override the weak and strong rankings: languages with a weak ranking of EPP(case) will sometimes allow OS when *MOVE is outranked by some constraint A that favors it (cf. (19a)), and languages with a strong ranking of EPP(case) will sometimes disallow OS when EPP(case) is outranked by some constraint B that disfavors it (cf. (19b)).

(19) a. A $>>*$ MOVE $>>\operatorname{EPP}($ case): if A favors OS, the weak ranking of EPP(case) is overruled

b. $B>>E P P($ case $)>*^{*} M O V E$ : if B disfavors OS, the strong ranking of EPP(case) is overruled

We will assume that the constraints that override the weak/strong rankings are related to restrictions imposed by the C-I and A-P systems, for which reason we will refer to them as interface constraints. The three interface constraints relevant for our present discussion are given in (20). These constraints all correspond more or less with notions found in (16) above: the constraint D-PRONOUN essentially adopts earlier claims that phonologically reduced pronouns cannot occur $v$ P-internally and replaces clause (16c,ii); the constraint ALIGNFOCUS, which is taken from Costa (1998), formalizes the well-known observation that new information tends to occur in the right periphery of the clause, and replaces $(16 \mathrm{c}, \mathrm{i})$ above; finally, H-COMPL expresses part of Holmberg's Generalization in (11), which Chomsky tries to capture by appealing to the notion of phonological border in $(16 \mathrm{c}){ }^{8}$

(20) a. D-PRONOUN: a reduced definite pronoun must be $v$ P-external: $*\left[{ }^{2} \mathrm{P} \ldots \operatorname{pron}_{[+\mathrm{def}]} \ldots\right]$.

b. ALIGNFOCUS (AF): the prosodically unmarked focus is the rightmost constituent in its clause.

c. H-COMPL: a head precedes all terminals dominated by its complement

Now we have everything in place to show how the weak and strong rankings in (18) can be overridden. First, consider the case in (19a), which can be illustrated by means of the Danish examples in (14) and (15), repeated here in a slightly different form as (21), in which the angled brackets indicate alternative placements of the object. Broekhuis (2000) has argued that Danish OS in (21a) is blocked by the weak ranking *MOVE $>>\operatorname{EPP}($ case). The fact that OS is nevertheless possible when the object is a definite pronoun is due to the fact that * MOVE is outranked by D-PRONOUN, which requires that the pronominal object be $v \mathrm{P}$ external.

\footnotetext{
${ }^{8}$ It is not entirely clear at present whether D-PRONOUN is imposed by the A-P or the C-I system. Diesing (1997) claims that definite pronouns are variables that cannot occur in the domain of existential closure, whereas, e.g., Vogel (2006b) claims that the need of leftward movement of definite pronouns is related to the phonological weight of the pronouns. Given that emphatically stressed definite pronouns do occur $v$ P-internally, we provisionally assume that we are dealing with a restriction imposed by the A-P system. Note further that the formulations of ALIGNFOCUS and H-COMPL are sloppy in the sense that they refer to the notion of linearity: since the constraints apply to the output of $\mathrm{C}_{\mathrm{HL}}$ and linearization is part of the phonological component, we should phrase the restriction in hierarchical terms. However, given that we assume a version of the universal base hypothesis, according to which asymmetric c-command corresponds to the linear notion of precedence, this is an acceptable simplification: (20b) states that the prosodically unmarked focus may not asymmetrically c-command any other constituent within its clause, and (20c) states that the head of a head-chain must c-command the head of the A-chain of its complement.
} 

Danish: D-PRONOUN $>>*$ MOVE $>>\operatorname{EPP}($ case $)$
a. Hvorfor læste Peter $<*$ artiklen $>$ aldrig $<$ artiklen $>$ ?
Why read Peter the.article never
b. Hvorfor læste Peter $<$ den $>$ aldrig $<*$ den $>$ ?
why read Peter it never

This shows that we can readily account for the fact that languages differ in the extent to which they exhibit OS: languages like Icelandic allow OS both with pronominal and lexical DPs due to the fact that they have a strong ranking of EPP(case), languages like Danish have the ranking D-PRONOUN $>*_{\text {MOVE }}>\operatorname{EPP}($ case) and therefore allow OS of pronouns only, and languages like Finnish-Swedish do not have any form of regular OS because *MOVE outranks both EPP(case) and D-PRONOUN. This gives rise to the macro-parameterization in Figure 4.

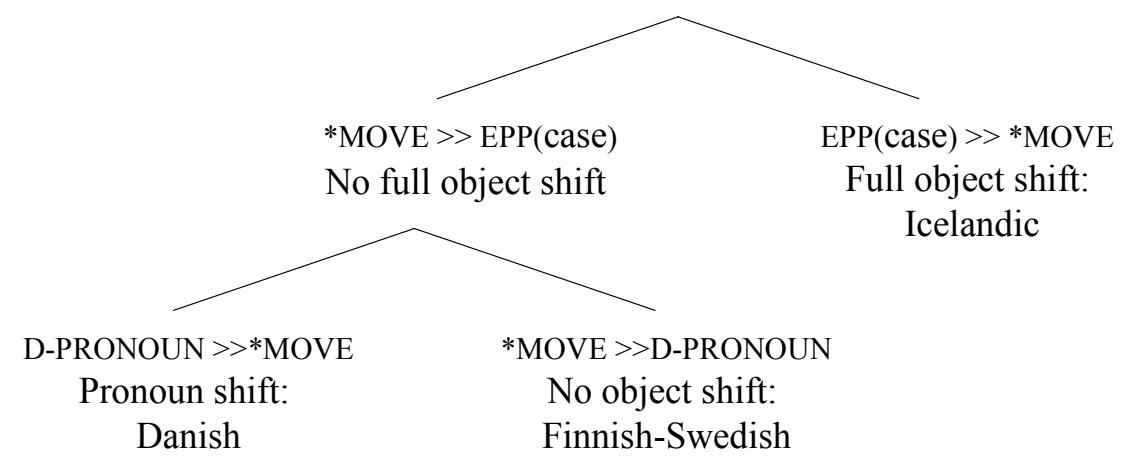

Figure 4: Macro-parameterization of languages with respect to object shift

Now, consider the case in $(19 b)$, which can be illustrated by means of the Icelandic examples in (9), repeated here in a slightly different form as (22), in which the angled brackets again indicate alternative placements of the object. By assuming that ALIGNFOCUS in (20b) outranks EPP(case), we account for the fact that OS is excluded when the object is part of the focus of the clause given that the high ranking of ALIGNFOCUS requires it to be the rightmost constituent in its clause.
Icelandic: $\mathrm{AF}>>\mathrm{EPP}($ case $)>>* \mathrm{MOVE}$
a. Jón keypti <*bókina $>$ ekki <bókina $>$.
Jón bought the book not
b. Jón keypti <bókina > ekki <*bókina>
bókina $\subset$ focus
bókina $\subset$ presupposition

Holmberg's generalization in (11b) instantiates another case of (19b); the Icelandic examples in (10), repeated here as (23a), can be accounted for by assuming that H-COMPL also outranks EPP(case). Given that H-COMPL and ALIGNFOCUS both disfavor OS, the ranking of these two constraints cannot be established on bases of the data discussed so far, which we have expressed by placing them within curly brackets. Example (23b) shows that Holmberg's Generalization also applies to Danish pronominal object shift, which can be accounted for by assuming that H-COMPL outranks D-PRONOUN.

(23) a. Icelandic: $\{\mathrm{H}-\mathrm{COMPL}, \mathrm{AF}\}>\mathrm{EPP}($ case $)>>*$ MOVE

Jón hefur $<*$ bókina $>$ ekki keypt $<$ bókina $>$.

Jón has the book not bought

b. Danish: H-COMPL >> D-PRONOUN $>>*_{\text {MOVE }>>\text { EPP(case) }}$

Hvorfor har Peter $<$ den $>$ aldrig læst $<*$ den $>$ ?

why has Peter it never read 
This subsection has shown that we can provide a descriptively adequate account of the Scandinavian OS data discussed so far by postulating the constraints in (17) and (20), which are in fact no more than alternative versions of assumptions that are already present in the current MP framework. Interestingly, the empirical scope of the present OT-account goes far beyond the data that motivated it. For example, the proposal leads us to expect that there are also OS-languages with the ranking EPP(case) $>>*$ MOVE $>$ H-COMPL; these languages resemble Icelandic in allowing non-pronominal OS, but differ from it by not being sensitive to Chomsky's (2001) version of Holmberg Generalization in (16c), that is, by allowing the object to cross a c-commanding $v^{*} \mathrm{P}$-internal verb. Broekhuis (2008) has argued that this expectation is indeed borne out, and that Dutch and German are languages of this type.

\subsection{The Interaction of Object Shift and Verb Movement}

The high ranking of H-COMPL in the constraint rankings of (23) does not only account for the fact that OS is excluded in complex verb constructions, but also accounts for the examples in (24), which show that whereas Icelandic also allows OS in embedded clauses, Danish does not. This contrast is related to a difference in verb movement between Icelandic and Danish. The fact that the finite verb precedes adverbial phrases like aldrei 'never' in (24a) shows that the finite verb undergoes V-to-I in embedded clauses in Icelandic; as a result, OS will satisfy $\mathrm{H}-\mathrm{COMPL}$ and is thus correctly predicted to result in an acceptable result. The fact that the finite verb follows adverbials like aldrig 'never' in (24b) shows that the finite verb does not undergo V-to-I in embedded clauses in Danish; as a result, OS will violate H-COMPL and is thus correctly predicted to be impossible.

$$
\begin{aligned}
& \text { a. Éf spurði af hverju Pétur læsi <pessa bók }>\text { aldrei } t_{\mathrm{V}}<\text { pessa bók }>\text {. } \\
& \text { I asked why Pétur read this book never } \\
& \text { b. Jeg spurgte hvorfor Peter }<* \text { den }>\text { aldrig læste }<\text { den }>\text {. } \\
& \text { I asked why Peter it never read }
\end{aligned}
$$

(Icelandic)

(Danish)

The fact that Danish pronominal OS can only occur in main clauses, as shown by the contrast between the Danish examples in (23b) and (24b), can therefore be related to the fact that Danish is an asymmetric V2-language.

It is important to note that this conclusion is only sound when V-movement applies in core syntax (contra Chomsky, 2004, and especially Boeckx \& Stjepanovic, 2001, who have claimed that head-movement in general is a PF phenomenon). A simple and in our view conclusive argument in favor of syntactic verb movement can be based on the fact discussed earlier that Icelandic OS is sensitive to the information structure of the clause. We have seen in Section 3.1 that Chomsky (2001) concluded from this that OS must be construed as part of core syntax given that "displacement rules interspersed in the phonological component should have little semantic effect". Since Scandinavian OS cannot apply when the main verb remains in $v^{*} \mathrm{P}$-internal position, it follows immediately that $\mathrm{V}$-to-I must also be a rule of core syntax; see also Den Dikken (2006/2007). Since we have already seen that Holmberg's generalization in (11b) cannot be accounted for by means of some condition on movement given that the intermediate stage given in (8) does involve movement of the object across the main verb, it must be rephrased as a filter on the output representation. This, in fact, is the only option in our current proposal.

In earlier accounts of Holmberg's Generalization, the observation that V-to-I must apply in order to license OS was normally considered the end of the story, whereas in the present approach it can be no more than half of the story given that there are in principle two ways in which H-COMPL could be satisfied: the first way is the one illustrated in (24b), where pronominal OS is blocked by the $v^{*} \mathrm{P}$-internal verb; the second way would be a case in which 
the verb is actually pushed up into the I-position by pronominal OS. A full account of Holmberg's Generalization thus requires an explanation of the fact that Danish does not employ the push-up option in embedded clauses. In order to account for this, we first have to provide an analysis of V-to-I. The constraints that we will use for this are given in (25).

(25) a. *STRAY FEATURE: amalgamate formal features of the functional heads with the root they are associated with.

b. LEXICALLY FILL TOP F (LFTF): the highest head position in an extended projection must be lexically filled.

c. NOLEXM: a $\theta$-role assigning head remains in its $\theta$-domain (a main verb does not move).

The constraint *STRAY FEATURE is a generalized version of the EPP-constraints involved in head movement: instead of postulating separate constraints like EPP(tense) or EPP(aspect), we simply require that the formal features in the extended projection of the verb (or other lexical categories) amalgamate with their lexical associate. The relative ranking of *STRAY FEATURE and ${ }^{*}$ MOVE will therefore determines whether the verbal root $\mathrm{V}$ will move into the higher functional heads (like $v$ or I) in its extended projection.

The constraint LEXICALLY FILL TOP F can be held responsible for the asymmetric V2property of languages like Danish: LFTF $>$ * MOVE $>$ * STRAY FEATURE predicts that in the absence of a complementizer the verb must be moved into the highest functional projection in the extended projection of the verb, whereas it will remain in situ otherwise. ${ }^{9}$ When we further assume that complementizers must be selected, and can therefore only appear in embedded clauses, it will follow that V2 must apply in main clauses (and in embedded clauses that are complementizer-less for one reason or other).

The third constraint, NOLEXM, is adapted from Grimshaw (1997) and goes back at least to Pollock (1989): its role is to block movement of main verbs, while still allowing movement of auxiliary and modal verbs, and it is used to account for the fact that in English V-to-I is restricted to modal and auxiliary verbs, that is, cannot apply to main verbs. The three constraints in (25) in tandem with the general economy constraint * MOVE suffice to provide a basic typology of V-to-I by defining 24 different rankings which produce six different typological patterns. This is illustrated in Table 1, which was calculated by hand (a new tool that may help in performing this kind of calculations is OTWorkplace; Prince \& Tesar 2010).

Table 1: V-to-I in the Germanic languages

\begin{tabular}{|c|c|c|c|c|c|}
\hline & RANKING & $\# 24$ & $\begin{array}{l}\text { MAIN } \\
\text { CLAUSES }\end{array}$ & $\begin{array}{l}\text { EMBEDDED } \\
\text { CLAUSES }\end{array}$ & EXAMPLE \\
\hline 1 & $\begin{array}{l}* \text { MOVE }>>\{* \text { STRAY FEATURE, LFTF }\} ; \\
\text { ranking NOLEXM not relevant }\end{array}$ & 8 & - & - & Japanese \\
\hline 2 & $\begin{array}{l}\text { LFTF }>>* \text { MOVE }>>* \text { STRAY FEATURE; } \\
\text { LFTF }>>\text { NOLEXM }\end{array}$ & 3 & + & - & $\begin{array}{l}\text { Dutch/German } \\
\text { Danish/Swedish }\end{array}$ \\
\hline 3 & NOLEXM $>>$ LFTF $>>*$ MOVE $>>*$ STRAY FEATURE & 1 & aux only & - & Proto-Germanic \\
\hline 4 & $\begin{array}{l}\text { *STRAY FEATURE }>>\left\{{ }^{*} \text { MOVE, NOLEXM }\right\} \\
\text { ranking LFTF not relevant }\end{array}$ & 8 & + & + & Icelandic \\
\hline 5 & $\begin{array}{l}\text { NOLEXM }>>\text { *STRAY FEATURE }>>*^{*} \text { MOVE; } \\
\text { NOLEXM }>>\text { LFTF }\end{array}$ & 3 & aux only & aux only & English \\
\hline 6 & LFTF $>>$ NOLEXM $>>*$ STRAY FEATURE $>>*$ MOVE & 1 & + & aux only & Proto-Indo-European \\
\hline
\end{tabular}

\footnotetext{
${ }^{9}$ Of course, the notion lexically filled in (25b) must be distinguished from the notion "phonetically realized". More specifically, it may be the case that a complementizer that is lexically present is phonetically empty as a result of the constraint TELEGRAPH; see section 2.2 for discussion. The constraint LEXICALLY FILL TOP F is similar to the nameless principle independently proposed in Zwart (2001:38).
} 
The first type arises when *MOVE outranks the two constraints that favor V-to-I, *STRAY FEATURE and LEXICALLY FILL TOP F, and is characterized by having no V-to-I at all. To our knowledge there are no languages of this type within the Germanic language family, but OVlanguages like Japanese will be good candidates.

The second and the third types are languages with V2 in main clauses only. The weak ranking of *STRAY FEATURE blocks V-to-I in embedded clauses, whereas the ranking of LFTF above *MOVE forces V-to-I in main clauses. The second and the third type differ in the relative ranking of NOLEXM and LFTF. The third type has the subranking NOLEXM $>>$ LFTF and therefore allows V2 with auxiliary and modal verbs only; to our knowledge there are no languages of this type within present-day Germanic, but Tonya Kim Dewey (p.c.) informs us that reconstructed Proto-Germanic is of this type; cf. Fortson (2004) and Dewey (2006). The second type has the subranking LFTF $>>$ NOLEXM, and allows V2 in main clauses with all verbs. Swedish and Danish as well as the Germanic OV-languages are examples of this type.

The fourth type arises when *STRAY FEATURE outranks the constraints that disfavor movement, NOLEXM and *MOVE, and is defined by allowing V-to-I with all finite verbs in all contexts. This type is instantiated by Icelandic.

The fifth and the sixth type arise when we have a strong ranking of *STRAY FEATURE, but NOLEXM outranks *STRAY FEATURE. This results in languages that normally have V-to-I with auxiliary and modal verbs only. The two types differ in the relative ranking of NOLEXM and LEXICALLY FILL TOP F. When the former outranks the latter, V-to-I is restricted to auxiliary and model verbs in all contexts: English is an example of this type. On the subranking LEXICALLY FILL TOP F >> NOLEXM, V-to-I of main verbs is restricted to main clauses, whereas aux-to-I may apply in all contexts. To our knowledge there are currently no Germanic languages of this type, but Tonya Kim Dewey (p.c.) again informs us that reconstructed Proto-Indo-European exhibits this behavior; cf. Fortson (2004) and Dewey (2006).

Let us now return to the question why Danish has the pattern in (26a) without pronominal OS and embedded V-to-I, rather than that in (26b) with pronominal OS and embedded V-to-I.

(26) a. Jeg spurgte hvorfor Peter aldrig læste den.

I asked why Peter never read it

b. Jeg spurgte hvorfor Peter læste den aldrig $t_{\mathrm{V}} t_{\text {den }}$.

I asked why Peter read it never

This question can now be answered by having a better look at the subrankings independently established so far. We have seen that the subranking in (23b), repeated here as (27a), correctly accounts for the following two facts: Danish only has pronominal OS and pronominal OS is blocked in complex verb construction by the non-finite main verb. Our discussion of Table 1 has further shown that the subrankings in $(27 b \& c)$ account for the fact that V-to-I is restricted to main clauses.

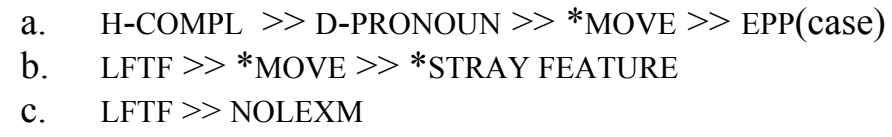

The question why Danish opts for the blocking of OS in (26a) instead of push-up of the finite main verbs in (26b) must be answered by appealing to the interaction of the independently motivated constraints in (27). The two obvious candidates that could handle this are D-PRONOUN and NOLEXM, given that the former favors pronominal object shift and the latter disfavors movement of main verbs: the subranking D-PRONOUN $>$ NOLEXM predicts that 
pronominal OS would push up the finite main verb into I, whereas the subranking NOLEXM $>>$ D-PRONOUN predicts that the main verb would block pronominal OS. From this we may conclude that that Danish has the subranking NOLEXM $>>$ D-PRONOUN. When we assume that Danish has the ranking in Tableau 8, where the dashed lines indicate that the constraints cannot be ordered yet on the basis of the data discussed so far, we will get the desired result.

Tableau 8: V-to-I and pronominal object shift in Danish embedded clauses

\begin{tabular}{|c|c|c|c|c|c|c|c|}
\hline & H-COMPL & LFTF & NOLEXM & D-PRONOUN & *MOVE & *STRAYF & EPP(case) \\
\hline $\begin{array}{l}\text { no pronominal OS } \\
\text { no V-to-I }\end{array}$ & & & & $*$ & & * & $*$ \\
\hline $\begin{array}{l}\text { pronominal OS } \\
\text { no V-to-I }\end{array}$ & $* !$ & & & & $*$ & $*$ & \\
\hline $\begin{array}{l}\text { no pronominal OS } \\
\text { V-to-I }\end{array}$ & & & $* !$ & $*$ & $*$ & & $*$ \\
\hline $\begin{array}{l}\text { pronominal OS } \\
\text { V-to-I }\end{array}$ & & & $* !$ & & $* *$ & & \\
\hline
\end{tabular}

For completeness' sake note that the suggestion in Tableau 8 that H-COMPL outranks NOLEXM has not been established yet. In Broekhuis (2008) it is argued that next to the type of OS discussed here, which he refers to as regular OS, there is second type of OS, which he refers to as short object, which is triggered by the $\varphi$-features on the verbal root $\mathrm{V}$, which does have the property of forcing V-to- $v$ in Danish. This can be accounting for by assuming that the constraint $\operatorname{EPP}(\varphi)$, which is responsible for short OS, is ranked between H-COMPL and NOLEXM. Since we do not have the space here to discuss short OS (which can be identified with the type of object movement identified for English by Johnson, 1991, and Lasnik, 1999a: ch.2/8), we refer the reader to Broekhuis (2008) for detailed discussion.

\subsection{Conclusion}

This section has shown that the minimalist EPP-features can readily be eliminated by postulating a set of EPP-constraints. As such, this is of course not a real gain as we simply replace one postulate by another, but Section 3.2 has shown that this results in a grammatical system with entirely different properties that is better equipped to capture language variation than the standard minimalist approach, and is also readily able to account for apparently optional movements like Scandinavian OS. Furthermore, Section 3.3 has shown by means of a discussion of the interaction between object shift and verb movement that the postulation of EPP-constraints may have wide ramifications throughout the grammatical system due to the fact that they may interact. Given space limitation we have not been able to make all evaluations explicit by means of tableaux, but these can been found in Broekhuis (2008) where a much more detailed discussion of object shift (including what has become known as scrambling in Dutch/German) can be found.

This section has given a first illustration of our claim at the end of Section 2.3 that the hybrid MP + OT model may substantially change our views on the properties ascribed to the generative and filtering device by traditional MP/OT. The proposed change in the MP system was of course rather limited: we simply replaced the postulate of EPP-features by that of EPPconstraints, while leaving the inviolable conditions on the operations of $\mathrm{C}_{\mathrm{HL}}$ intact. However, the hybrid system requires that we investigate whether the use of such conditions is the optimal way of restricting the operations of $\mathrm{C}_{\mathrm{HL}}$ or whether we can further simplify the operations of the computational system by accounting for the restriction on these operations by means of an optimality-theoretic evaluation. In the next section, we will therefore investigate whether it would be profitable to reformulate the locality restrictions on case assignment in an OT-fashion as violable constraints on output representations. 


\section{Local Domains and Case Theory}

This section, which builds on earlier work by Woolford, shows how the hybrid MP + OT model allows us to capture an interesting typological difference with respect to the possibility of licensing nominative objects, namely that some languages allow $\mathrm{T}$ to value nominative on an object when the subject has inherent case, but other languages do not. We preserve from MP the notion that all structural cases must be licensed by a head in an Agree relation under c-command. ${ }^{10}$ We preserve the Minimal Link Condition on case-licensing, but split it into two. We build into the basic Agree relation a weak but inviolable version of the Minimal Link Condition which allows T to probe past a closer DP with inherent case. A strong version of the Minimal Link Condition which blocks probing past any closer DP, even one with inherent Case, is formulated here as a violable constraint. This approach allows us to capture the fact (which cannot be captured by a parameter) that a closer dative blocks nominative licensing/valuation on objects in some constructions in Icelandic, but not in others.

\subsection{The Typological Problem}

It is well-known that languages such as Icelandic and Hindi allow nominative objects in dative subject constructions:
a. Barninu batnaði veikin.
child-DAT recovered-from disease-NOM
'The child recovered from the disease.'
b. Siitaa-ko laRke pasand the.
Sita-DAT boys-NOM.masc like be(past.masc.pl)
(Yip et al. 1987: 223)
'Sita liked the boys.'
(Mahajan $1991(7)$ )

[Icelandic]

What is not so well-known is that in other languages, such as Faroese, dative subject constructions take structural accusative objects. We will argue that nominative licensing is blocked by the closer dative in these constructions.
a. Mær tørvar góða hjálp
me.DAT needs.3sg good.ACChelp.ACC
'I need good help.'
b. Mær líkar hana væl. me.DAT likes.3sg her.ACC well 'I like her a lot.'

[Faroese]

(Thráinsson et al. 2004: 256)

[Faroese]

(Thráinsson et al. 2004: 255)

Ergative subject constructions divide into the same two types; cf. Legate (2006) and Woolford (2003b/2007). Languages such as Inuit and Hindi allow nominative objects in all constructions where the subject has inherent case, dative or ergative. ${ }^{11}$ Note that Hindi manifests the same agreement pattern as Icelandic, where the verb agrees with all and only nominatives, regardless of whether the nominative is a subject or an object.

\footnotetext{
${ }^{10}$ Retaining the MP requirement that all cases on arguments must be licensed by a head in a legal Agree configuration eliminates the possibility of the generator generating candidates with random cases on arguments, arguments with no case at all, inserted (but unlicensed) cases, and unlicensed default case in syntax. At spell-out (PF) an independent decision is made as to whether to spell-out the case feature from syntax.

${ }^{11}$ For a summary of the extensive evidence that ergative is an inherent Case like the dative, see Woolford (2006).
} 

$\begin{array}{llc}\text { a. Juuna-p puisit } & \text { aallaa-v-a-i } \\ \text { Junna-ERG } & \text { seals.NOM } & \text { shoot-ind-tr-3sg.3pl }\end{array}$
'Juuna shot the seals.'
khaayii thii.
eat.perf.fem be.past.fem
Ram-ERG bread.fem.NOM
'Ram had eaten bread.'
(Mahajan 1990:73)

In contrast, ergative languages such as Warlpiri do not allow nominative objects (Legate 2006), and this is true of many other Australian languages as well according to Godard (1992). Objects in Warlpiri are cross-referenced with an accusative pronominal clitic, and not with the agreement that cross-references nominative subjects (in contrast to the pattern in Hindi above):
a. Ngaju ka-rna
wangka-mi.
I.NOM pres-1sgAgr speak-nonpast
'I am speaking.'
Kurdu-ngku ka-ju
child-ERG
'The child sees me.'
pres-1sg.ACC see-nonpast me.ACC
nya-nyi ngaju.

(Hale $1982(9 \mathrm{a}))$

[Warlpiri]

(Simpson 1991:99)

Our goal here is to provide a simple account of this typological difference: that some languages allow nominative objects in constructions where the subject has inherent case, and other languages do not. We will argue that this difference follows from a difference in the ranking of a violable version of the Minimal Link Constraint.

The strategy is as follows. First, the Agree relation in MP from Chomsky (2000) is updated and formulated with only a weak version of the Minimal Link Condition, so that $\mathrm{T}$ is allowed to probe past a closer dative in order to value nominative on a further DP (Section 4.2). Where a closer dative blocks $\mathrm{T}$ from valuing nominative on an object, the claim here is that this is due to the application of a stronger, but violable version of the MLC, the Strong Minimal Link Constraint (Section 4.3). This violable constraint does not get a chance to apply in many constructions in languages such as Icelandic and Hindi, because it is outranked by another violable constraint, the Least Marked Case Constraint. ${ }^{12}$ This constraint requires the selection of the least marked case that can be licensed on any DP, and thus favors nominative over accusative (Section 4.4). We will show that this constraint produces all of the effects normally attributed to Burzio's Generalization (Section 4.5). The details of the analysis are presented in section 4.6, where we show how a difference in the relative ranking of these two violable constraints produces the typological difference between languages which do and do not allow nominative objects in clauses with a dative or ergative subject (a subject with inherent case). We show in Sections 4.7 and 4.8 that, regardless of their ranking, both constraints are active in both types of languages. That is, the lower ranked constraint must be obeyed as long as it does not conflict with the requirements of the higher ranked constraint. Section 4.9 discusses whether the constraints proposed in this section apply to derivations or representations, and we dispel the myth that MP necessarily evaluates derivations, bottom up and step by step, while OT necessarily evaluates representations. We conclude in Section 4.10 by summarizing the benefits of the present approach.

\footnotetext{
${ }^{12}$ A reviewer points out that in a technical sense, every constraint applies in OT in the sense that every constraint assesses every candidate, as indicated in the tableaux. When we say that a constraint does not get a chance to apply, we mean that it has no effect on the outcome because constraints ranked above it select the optimal candidate.
} 


\subsection{The Agree (probe-goal) relation and case}

This section discusses a number of assumptions concerning case valuation that will be crucial for the analysis to be developed. We assume, as in MP, that the case feature of a DP is initially unvalued, and must be valued in an Agree (probe-goal) relation with a ccommanding head, subject to locality. However, it will be crucial in this section to retain the older view that the case features of $\mathrm{T}$ and the verb are initially valued, as nominative and accusative respectively (rather than adopting the assumption in Chomsky, 2008, that the case features of heads are also initially unvalued and that case is an automatic reflex of agreement). One desirable effect of this, as we will see below, is that it removes any need for case-assigning heads to enter into an Agree relation, since valued uninterpretable features can simply delete at the interface (Chomsky 2008). As for the definition of the Agree relation itself, rather than adopting the most recent formulation in Chomsky (2008), which is designed to accommodate multiple agree, ${ }^{13}$ we update the formulation of Agree from Chomsky (2000:122), which restricts a head from establishing an Agree relation with anything except the closest DP that has a matching case feature. This updated formulation of Agree in (32) is technically new, but it closely follows the original notion of "closest match" in claiming that a head can only probe until it finds a case feature that it can value, and after that, it must stop. In (32), this is informally formulated for case valuation.

Agree relation for case valuation:

A case-assigning head can enter into a probe-goal relation under c-command only with the closest DP that has an unvalued case feature

When there is no closer DP, which is the situation in a simple unaccusative construction, nothing blocks $\mathrm{T}$ from licensing nominative case under c-command, even to a DP inside the VP. This occurs in unaccusative constructions in Italian and in general across languages (Burzio 1986). Note that this even holds in unaccusative constructions in Faroese, as in example (33), despite the fact that in Faroese, nominative objects are blocked in dative subject constructions like (29a) above:

$$
\begin{array}{lcc}
\text { Tað eru komnir nakrirgestir } & \text { í gjár. } & \text { [Faroese] } \\
\text { there are-pl come-pl some guests-NOM.pl } & \text { yesterday } \\
\text { 'Some guests came yesterday.' } & \text { (Jonas, p.c.) }
\end{array}
$$

When a closer DP is present, it will block $\mathrm{T}$ from probing further if it has an unvalued case feature, as in (34a), but not if its case feature is already valued, as is the situation with a DP with inherent Case, as in (34b). Inherent case is valued in connection with theta marking (Chomsky 1995:114), and we assume this occurs at the moment the DP is merged.

$$
\begin{aligned}
& \text { a. T[nom]DP-[u case] DP-[u case] } \\
& \text { b. T[nom] DP-[dative] DP-[u case] }
\end{aligned}
$$

The formulation of Agree in (32) therefore captures the fact that $\mathrm{T}$ can value nominative on an object in Icelandic when there is a closer dative DP, regardless of whether or not that dative intervenes between $\mathrm{T}$ and the nominative in the surface word order (a point that will be important below):

\footnotetext{
${ }^{13}$ Likewise we do not adopt the associated assumption in Chomsky 2008 designed for multiple agree that inherently case-marked DPs have an additional structural case feature that needs to be valued.
} 

a. Sumum gömlum mönnum líkar/líka pípuhattar. some.Dat.pl old.Dat.pl men.Dat.pl like.3sg/3pl top hats.Nom.pl 'Some old men like top hats.'
(Ussery 2009)
b. Рað líkar/líka sumum gömlum mönnum pípuhattar. expl like.3sg/3pl some.Dat.pl old.Dat.pl men.Dat.pl top hats.Nom.pl 'There like some old men top hats.'
(Ussery 2009)

In section 4.7, we discuss a more complex type of Icelandic example that has led some (including Chomsky 2000:130) to incorrectly conclude that a surface intervening dative always blocks $\mathrm{T}$ from establishing an Agree relation with a further DP. We will show that such examples violate not the universal Agree requirements, but rather a separate, violable constraint, which we will refer to as the Strong Minimal Link Constraint and which will be developed in the next section. The approach developed here correctly predicts when such a violation is and is not tolerated in Icelandic.

\subsection{The Strong Minimal Link Constraint}

Given that the Agree relation defined in (32) allows T to probe across a subject with inherent case, the question now is what blocks nominative objects in dative subject constructions in Faroese? The answer, we propose, is the existence of a strong version of the Minimal Link Condition, formulated as a violable constraint, the Strong Minimal Link Constraint in (36). This violable constraint prohibits $\mathrm{T}$ from probing past any closer DP, regardless of whether or not its case feature is valued.
Strong Minimal Link Constraint (violable constraint):
A probe (case-assigning head) is blocked from establishing an Agree relation with a goal (DP) if there is a closer potential goal (DP), regardless of whether or not the head can enter into an Agree relation with that closer goal.

In Faroese, the Strong MLC constraint is ranked high, and blocks $\mathrm{T}$ from probing past a dative. Thus, in experiencer constructions with a dative subject, the verb is the only head that can value case on the object, producing a dative-accusative pattern. The valued case feature on $\mathrm{T}$ in (37) simply deletes at the interface.

$$
\mathrm{T}[\text { nom }] \quad \text { DP-dative } \quad \mathrm{V}[\mathrm{acc}] \quad \text { DP-accusative }
$$

[Faroese]

In section 4.5, we will see that, although lower ranked in Icelandic, the Strong MLC does apply when it does not conflict with another higher ranked constraint, the Least Marked Case Constraint, to which we now turn.

\subsection{The Least Marked Case Constraint}

One of the two primary types of constraints in OT is markedness constraints, which select a less marked element over a more marked element. Since nominative is a less marked case than accusative, it should be preferred over accusative in a situation where either case could be licensed. ${ }^{14}$ We encode this generalization in our hybrid approach as a violable constraint, the Least Marked Case Constraint:

\footnotetext{
${ }^{14}$ Nominative is the least marked case. It appears to be present in every language, assuming that subjects labeled with absolutive case are actually nominative (Bittner 1991). This is not true for any other case; for example, Basque does not use accusative case (Bok-Bennema 1991). Moreover, nominative (absolutive) is more likely to be morphologically unmarked in languages than any other case (e.g. Blake 2001).
} 
Least Marked Case Constraint (violable constraint): ${ }^{15}$

When there is a choice of cases that could be valued on a DP, select the least marked of these cases.

In a clause with a dative subject, the Least Marked Case Constraint favors the derivation/representation in which the object gets nominative.

$$
\text { T[nom] DP-dative } \quad \mathrm{V}[\mathrm{acc}] \quad \mathrm{DP}-[\mathrm{nom}]
$$

The requirements of the Least Marked Case Constraint conflict with those of the Strong MLC; section 4.5 gives the details of how ranking this constraint above the Strong MLC makes the right predictions for Icelandic in a variety of constructions. Since MP already has violable constraints (called economy constraints in MP) which apply 'if possible', what we add to MP by adopting an OT-evaluation is the ability to rank such constraints, so as to govern the relative priority of their application when their requirements conflict. This will be crucial in the analysis in Section 4.6 of the difference between Icelandic and Faroese. Before we turn to this analysis, however, we provide additional motivation for adding the Least Marked Case Constraint in (38) to the grammar.

\subsection{Deriving Burzio’s Generalization}

Woolford $(2001 ; 2003 a, b)$ argues that the Least Marked Case Constraint produces all of the effects attributed to Burzio's (1986) Generalization, without its over- and under-generation problems. To see this, let us begin by reviewing the data that motivated Burzio's Generalization. The primary fact is that unaccusative subjects get nominative case, even if they remain in situ inside the VP as in Italian.

$$
\begin{array}{ll}
\text { All'improvviso è entrato un uomo alla finestra. } & \text { [Italian] } \\
\text { suddenly } \quad \text { entered a man.nom from the window } & \\
\text { 'Suddenly a man entered from the window.' } \quad \text { (Belletti 1988 (17)) }
\end{array}
$$

In (40), there are two heads ( $\mathrm{T}$ and the verb) that are known to license structural case in other constructions, and under the original formulation of Relativized Minimality (Rizzi 1990), the closer head (the verb) is expected to block the further head (T), but it does not here. To deal with this problem, Burzio (1986) postulated that the normal accusative licensing ability of the verb is not available in this construction (and that this somehow nullifies the blocking effect expected under Relativized Minimality). As to why the verb lacks its normal accusative case feature in unaccusatives and passives, Burzio noted that both constructions lack an external argument, and he thus proposed that the verb can license structural accusative case if and only if an external argument is present. This idea was then built into MP by postulating that the light verb $v$ (the head that introduces external arguments), rather than the verbal root $\mathrm{V}$, introduces the accusative case feature into the structure.

Since 1986, many exceptions to the original formulation of Burzio's Generalization have been pointed out. Accusative case can be licensed without the presence of an external

\footnotetext{
${ }^{15}$ The Least Marked Case constraint is formulated here in the style of economy constraints in MP. In pure OT, the formulation would be simplified because there is no need to include a direction to compare forms, since that is built into the architecture of OT. In addition, constraints also do not require one to consult a hierarchy; instead, constraints may be formulated based on a hierarchy, and then simply apply. Based on the markedness hierarchy of structural cases, accusative $>$ nominative, this constraint is formulated in Woolford 2001 as simply *accusative. There is no constraint against the least marked element in a hierarchy, following Gouskova (2003).
} 
argument (e.g. in experiencer subject constructions in English and Faroese). ${ }^{16}$ Moreover, accusative case is not always licensed in the presence of an external argument; an example of this is the ergative-nominative construction shown above in (30), with the pre-movement structure in (41). ${ }^{17}$

$$
\left[\begin{array}{lllll}
\mathrm{T}_{[\mathrm{nom}]} & \text { DP-ERGATIVE } & \mathrm{V}_{\text {[acc] }} \ldots \mathrm{V}_{[\text {acc] }} & \text { DP-NOMINATIVE }
\end{array}\right]
$$

There has been a great deal of work on Burzio's Generalization effects since 1986 and most of this work has reached the same conclusion, namely that there is actually no relation between the ability of the verb to assign accusative case and the presence of an external argument; see the papers collected in Reuland (2000) and summaries of many of the proposals in the literature in Woolford (2003a). Instead, there is currently fairly widespread agreement (including Burzio 2000) that the actual descriptive generalization is something like (42):

$$
\text { T must license nominative case (if possible). }
$$

Most proposals that incorporate the generalization in (42) into the grammar attribute it to T, by requiring that $\mathrm{T}$ establish an Agree relation with some DP; see the discussion in Woolford (2003a). But why should T be special in this way? An alternative perspective would be to say that it is not $\mathrm{T}$ that is special, but nominative, because it is the least marked case. The explanation for the effects that motivated Burzio's Generalization are actually the result of the fact that it is more "economical" to use the less marked nominative than a more marked case; cf. Woolford (2001; 2003a,b).

Adding the Least Marked Case Constraint to the list of violable constraints thus removes any need to require $\mathrm{T}$ to discharge its nominative feature, or to stipulate that certain verbs (in certain languages) carry an accusative case feature while others do not. Instead, the theory will make the right predictions if all heads optionally make use of the case feature they carry. Under the assumption noted above, that heads are merged with a valued case feature, the case feature of $\mathrm{T}$ will simply delete at the interface, as any valued uninterpretable feature does in Chomsky (2008).

Let us now turn to the details of how these two violable constraints Least Marked Case Constraint and Strong MLC introduced in Sections 4.3 and 4.4 produce the typological difference between languages with nominative versus accusative objects in constructions with inherently case-marked subjects described in Section 4.2.

\subsection{The Analysis}

The typological difference between dative-nominative languages like Icelandic and dativeaccusative languages like Faroese (and the parallel difference between ergative-nominative and ergative-accusative languages) reduces to a difference in the relative ranking of the Least Marked Case Constraint and the Strong MLC. In a clause where the subject has inherent case, these constraints determine which head, $\mathrm{T}$ or $\mathrm{V}$, gets to value structural case on the object. In Icelandic, the Least Marked Case Constraint takes priority, so that nominative is used whenever it can be legally licensed. In Faroese, the Strong MCL takes priority, so that any closer DP blocks T from reaching an object DP.

\footnotetext{
${ }^{16}$ Chomsky (2008) deals with this by locating the accusative case feature on the highest $\mathrm{v}$ of any transitive construction, including transitive experiencer subject constructions. He refers to this highest $v$ as $v^{*}$.

${ }^{17}$ Thus the prediction of the original formulation of Relativized Minimality (Rizzi 1990), that a closer head should block a further head from licensing case, is not born out. Fortunately, this prediction does not follow from the revised version of Relativized Minimality (Rizzi 2001), which, like the Minimal Link Condition, proposes that it is a closer goal (not a closer probe) that will block an Agree relation.
} 
(43) a. Constraint Ranking in Icelandic: Least Marked Case Constraint $>>$ Strong MLC

b. Constraint Ranking if Faroese: Strong MLC $>>$ Least Marked Case Constraint

In Icelandic, the higher ranked Least Marked Case Constraint (which favors nominatives) eliminates the (b)-candidate in Tableau 9, because it uses a more marked case, accusative. This leaves the (a)-candidate with a dative-nominative pattern, as the winner. Its violation of the lower ranked constraint is irrelevant (and thus shaded in the tableau below). ${ }^{18}$

Tableau 9: Icelandic Experiencer Subject Constructions

\begin{tabular}{|ll||c|c|}
\hline T & DP-dat V DP- & LEAST MARKED CASE & STRONG MLC \\
\hline \hline a. & T DP-dat V DP-nom & $*$ \\
\hline b. & T DP-dat V DP-acc & $* !$ & \\
\hline
\end{tabular}

The result is the reverse in Faroese, because the ranking of these two violable constraints is reversed. Here the higher ranked Strong MLC eliminates the (a)-candidate in Tableau 10 because it prohibits probing past the closer dative. This leaves the (b)-candidate with a dative-accusative pattern as the winner, and its violation of the lower ranked constraint is irrelevant.

\section{Tableau 10: Faroese Experiencer Subject Constructions}

\begin{tabular}{|c|c|c|}
\hline T DP-dat V DP- & STRONG MLC & LEAST MARKED CASE \\
\hline T DP-dat V DP-nom & $* !$ & \\
\hline $\begin{array}{lll}\text { b. } & \text { T DP-dat V DP-acc }\end{array}$ & & * \\
\hline
\end{tabular}

To show that this OT approach is superior to a parametric approach where these constraints would be set at 'off' or 'on' for each language, we need to see evidence that the lower ranked constraint in each language is still active. That is, it applies whenever the higher ranked constraint does not make the decision. We turn to this evidence in Sections 4.7 and 4.8.

\subsection{The Lower Ranked Least Marked Case Constraint Remains Active in Faroese}

In Faroese, although the Strong MLC outranks the Least Marked Case constraint, there is evidence that the lower ranked constraint is still active, and not set at 'off' as a parameter. This evidence takes the form of examples where the Least Marked Case constraint gets to make the decision. One kind of example is simple unaccusative constructions. Since there is no closer DP neither derivation violates the Strong MLC and the decision of whether T or the verb gets to value the case of the DP therefore passes down to the lower ranked Least Marked Case constraint.

\section{Tableau 11: Faroese Unaccusative Constructions}

\begin{tabular}{||llll||l|c||}
\hline T & V & DP- & STRONG MLC & LEAST MARKED CASE \\
\hline \hline a. ${ }^{\circ}$ & T & V & DP-nom & & \\
\hline b. & T & V & DP-acc & & $* !$ \\
\hline
\end{tabular}

\footnotetext{
${ }^{18}$ We have ignored a possible (c) candidate in this tableau where the inherent dative case is replaced by a nominative and the object is accusative. That candidate would be eliminated by a higher ranked faithfulness constraint Max (dative) in Icelandic. See Woolford 2001. Note that, following MP, the generator will not produce any candidate with a case that is not licensed by a head in a legal Agree relation.
} 
The Least Marked Case constraint selects the (a)-candidate with nominative over the (b)-candidate with accusative, because nominative is the less marked case. This is why unaccusative subjects do not get accusative case even in Faroese type languages; cf. example (33).

An important consequence of this approach is that it removes the need to claim that unaccusative verbs cannot license accusative case. All verbs potentially license accusative case. Moreover, there is no need to allow parametric variation in the case licensing/valuing capacity of any type of head across languages under this approach: differences in the case patterns that surface follow from differences in the relative ranking of the relevant violable constraints (see Woolford 2001, 2003a,b, 2007).

\subsection{The Lower Ranked Strong MLC Remains Active in Icelandic}

This section provides evidence that the Strong MLC, which is lower ranked in Icelandic, remains active, applying in constructions where the higher ranked Least Marked Case Constraint does not narrow the possible derivations down to one. This occurs when there are two candidates that use nominative case for a particular DP, but different Ts that may value that nominative. The Strong MLC then selects which derivation is more "economical".

Before we begin, we need to establish that the standard assumption in GB (e.g. Chomsky 1986) that non-finite $\mathrm{T}$ lacks a nominative case feature was incorrect. We now know that a non-finite $\mathrm{T}$ can value nominative case on its object in a dative subject construction (Jónsson 1996). We see this in example (44), where only the embedded nonfinite $\mathrm{T}$ can license/value nominative case on the embedded object, because the matrix $\mathrm{T}$ uses its nominative feature to value the case of the matrix subject. ${ }^{19}$

$$
\begin{aligned}
& \text { Hann hafði talið [Jón-i líka pessir sokkar ]. } \\
& \text { He-nom had.sg believed John-DAT to-like these socks-NOM }
\end{aligned}
$$

Jónsson (1996: 170)

Given that non-finite $\mathrm{T}$ can license nominative on an object, situations arise in which the grammar must make a decision as to whether a finite matrix $\mathrm{T}$ or an embedded non-finite $\mathrm{T}$ values nominative case on an embedded object, as in the structure in (45), exemplified by the examples in (46).

$$
\begin{aligned}
& {\left[\mathrm{T}_{[\mathrm{nom}]} \text { DP-DAT } \mathrm{V}\left[\mathrm{T}_{\text {[nom] }} \text { DP-DAT } \mathrm{V} \text { DP-NOM ] }\right]\right.} \\
& \text { a. }{ }^{* \text { *? }} \text { Mér virðast [stráknum líka pessir bílar ] } \\
& \text { me-DAT seem.3pl the boy-DAT like these cars-NOM } \\
& \text { 'It seems to me that the boy likes these cars.' (Watanabe 1993: 418) } \\
& \text { b. *Mér fundust [henn-i leiðast peir.] } \\
& \text { me-DAT seemed.3pl she-DAT be-bored they-NOM } \\
& \text { 'I thought she was bored with them.' } \\
& \text { (Taraldsen 1995 (40)) }
\end{aligned}
$$

The examples in (46) show that the matrix T cannot agree with the embedded nominative DP in the construction in (45). This is predicted by the analysis developed here, as we see in Tableau 12 below, where the lower T wins the competition to value case on that DP (and thus agreement is not possible with the upper $\mathrm{T}$ ). The (a)-candidate in Tableau 12, where the matrix $T$ values nominative on the embedded object (indicated here by coindexing), incurs two violations of the Strong MLC because there are two closer dative DPs. In contrast, the

\footnotetext{
${ }^{19}$ It remains true, however, even in Icelandic, that the subject of a non-finite clause cannot be overt except in ECM constructions. The explanation for this fact remains unclear, but it appears to have nothing to do with the ability of a non-finite $\mathrm{T}$ to license nominative case, contra the assumption in GB (Chomsky 1986).
} 
(b)-candidate, where the embedded $\mathrm{T}$ values nominative on that object, incurs only one violation because there is only one closer dative DP, and thus wins the competition. The (c)candidate, in which the object gets accusative, is eliminated by the higher ranked Least Marked Case constraint. Thus we see that the Strong MLC is active in Icelandic, making the decision when the higher ranked Least Marked Case constraint cannot.

Tableau 12: Icelandic

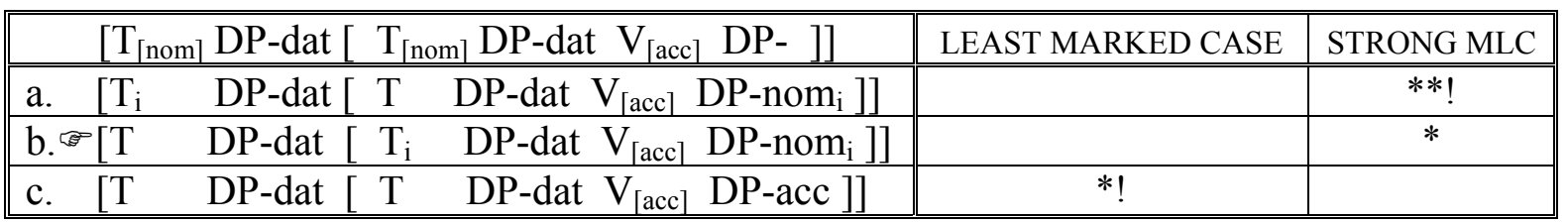

In the winning candidate in (b), where the non-finite $T$ values the nominative object, the matrix $\mathrm{T}$ shows only $3 \mathrm{sg}$ default agreement (since it does not establish an Agree relation with any argument) and non-finite $T$ never shows morphological agreement:

$$
\begin{array}{llll}
\text { Mér fannst }[\text { henn-i } & \text { leiðast } & \text { peir.] } \\
\text { me-DAT seemed.3sg she-DAT } & \text { be-bored } & \text { they.NOM } \\
\text { 'I thought she was bored with them.' } & \text { (Taraldsen } 1995 \text { (39)) }
\end{array}
$$

Although the matrix $\mathrm{T}$ loses the above competition in Tableau 12, there are other constructions in which it is possible for a matrix $\mathrm{T}$ to value nominative inside an embedded non-finite clause in Icelandic. Chomsky (2008:143) notes that $\mathrm{T}$ can probe under c-command into a lower phase or even into a lower clause in principle, if not blocked by a closer DP. This occurs successfully in raising examples like (48), where the matrix verb optionally agrees with the embedded nominative object:

$$
\begin{aligned}
& \text { Jón-i virðast [ } \mathrm{t} \text { vera taldir [ } \mathrm{t} \text { líka hestarnir]. } \\
& \text { John-dat seemed.3pl be believed like horses.nom } \\
& \text { 'John seems to be believed to like horses.' (Schütze 1997: 108-109) }
\end{aligned}
$$

This example differs from those in (46) above in that there is only one dative DP present. Before movement, that dative is located below $\mathrm{T}$ in the embedded clause. As a result, that dative intervenes in candidate (a), where the matrix $T$ enters into an Agree relation with the embedded object, and in candidate (b), where the embedded T enters into an Agree relation with the embedded object, and thus both candidates incur one violation of the Strong MLC. Thus there is a tie. This is consistent with the fact that agreement is optional in examples like (48); cf. Ussery (2009). ${ }^{20}$

Tableau 13: Icelandic Raising Example

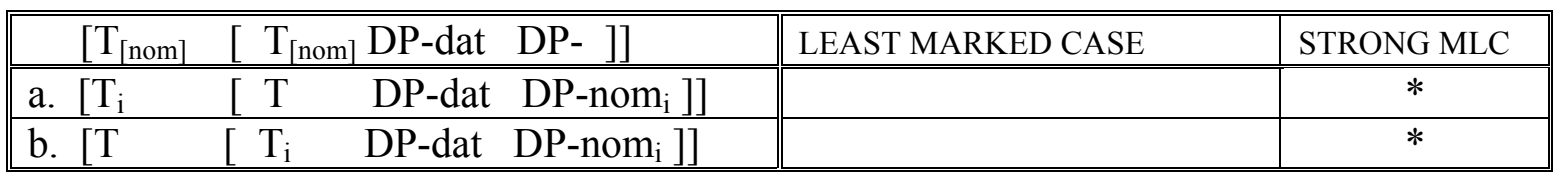

\footnotetext{
${ }^{20}$ Agreement is actually always optional with nominative objects in Icelandic according to Ussery's (2009) survey at the University of Iceland. However the percentage of speakers who prefer agreement in the raising constructions in (48), 36\%, is lower than the $47 \%$ who prefer agreement in simple monoclausal dative subject construction such as (35a) above. Note that the situation in Tableau 13 is similar to that in Tableau 3 in that the evaluation predicts that both constructions may occur but is silent on the relative frequency of the two. We will therefore not attempt to account for the rates of morphological spell-out of agreement here; we merely use the possibility of agreement as evidence that an Agree relation can be established with the relevant $\mathrm{T}$.
} 
We can eliminate an alternate hypothesis assumed in Chomsky $(2000 ; 2008)$ that the ungrammaticality of the examples in (46) is due to fact that the closer dative intervenes in the surface string (in contrast to the raising example in (48)). There is independent evidence from examples such as (49), where an expletive subject is present, that the mere presence of an intervening dative in the surface string is not sufficient to block nominative licensing in Icelandic. ${ }^{21}$ Here the verb can agree with the nominative object across the intervening dative:

$$
\begin{aligned}
& \text { Pað líkuðu einhverjum pessir sokkar. } \\
& \text { there liked.pl somebody-DAT these socks-NOM } \\
& \text { 'Somebody liked these socks.' }
\end{aligned}
$$

(Jónsson 1996: 153)

This example is predicted to grammatical under the hybrid MP + OT analysis presented here for the same reason that we saw above for the same kind of example without an expletive (e.g. (35a)). With only one T present, the higher ranked Least Marked Case Constraint must select the derivation where that $\mathrm{T}$ values nominative on the object, because the only alternative is the derivation in (b) where the verb values accusative:

\section{Tableau 14: Icelandic Experiencer Subject Constructions}

\begin{tabular}{|l||c|c||}
\hline there T DP-dat V DP- & LEAST MARKED CASE & STRONG MLC \\
\hline a. ${ }^{\circ}$ there T DP-dat V DP-nom & & $*$ \\
\hline b. there T DP-dat V DP-acc & $* !$ & \\
\hline
\end{tabular}

\subsection{Derivations or Representations}

Let us now turn to the question of whether the Strong MLC and the Least Marked Case constraint proposed above apply to derivations or representations. Before we do so, however, let us dispel the common myth that MP intrinsically evaluates derivations, bottom up and step by step, while OT necessarily evaluates completed derivations (representations). Chomsky makes this clear for his version of MP: "Generation of an expression is not strictly "bottomup," because of the parallelism of operations. (Chomsky 2007:6)"; “All operations within the phase are in effect simultaneous"; "their applicability is evaluated at the phase level (Chomsky 2001:24)." Prince and Smolensky (1993/2004) designed OT to evaluate completed derivations; however, that work mentions that it would also be compatible with the overarching principles of OT to implement the theory in a different way, with step by step derivation and evaluation (Prince and Smolensky, 1993: 94-95; see also Heck \& Müller 2000 for an early implementation of this idea). A version of this alternative, known as Harmonic Serialism, has been developed recently in McCarthy (2007/2008), who argues that it is more restrictive than classic OT in desirable ways. Under Harmonic Serialism, only one change at a time can occur (e.g. deletion or insertion of a feature) and any change must lead to an improvement, the best possible one-step improvement. Thus the decision as to whether to evaluate completed representations or to evaluate each step of a derivation is independent of whether one works in MP or OT, and, consequently, one might also take either approach in a hybrid theory.

\footnotetext{
${ }^{21}$ There is, nevertheless, a small reduction in the percentage of speakers who prefer morphological agreement in expletive constructions where the dative remains in situ and intervenes on the surface, as in (35b), according to Ussery (2009).
}
a. DP-dative T V DP-nominative
b. Expletive T V DP-dative DP-nominative
$46 \%$ agreement $35.8 \%$ agreement 
With respect to the hybrid approach to case valuation developed in this section, the Strong Minimal Link Constraint would apply correctly to completed representations under the version of MP in Chomsky 2000 because a DP in Spec TP was defined as closer to T than an object (Chomsky 2000). However, under the version of MP in Chomsky 2007 where an Agree relation can only be established under strict c-command, the Strong Minimal Link Constraint cannot apply to completed representations because a dative subject that has moved above $\mathrm{T}$ will not intervene between $\mathrm{T}$ and a nominative object, and thus cannot block $\mathrm{T}$ from probing past it. The Strong MLC would thus have to apply derivationally, at some point before the dative is moved above T. Nevertheless, there is a way to make the Strong MLC apply correctly even to completed derivations in this more recent version of MP if we take advantage of copy theory and add the idea that even an copy of a moved dative potentially blocks T from establishing an Agree relation with a lower object: [ DP-dative T DP- ].

\subsection{Summary of Benefits}

In this section, we have seen that adding to MP the ability to rank violable constraints (which already exist in MP under the name economy constraints) produces desirable results of several types. By splitting up the Minimal Link Condition into two separate conditions, one weak but inviolable and the other strong but violable, and by ranking the latter with respect to a new violable constraint which requires the selection of the least marked case that can be licensed, we not only derive Burzio's Generalization (and predict its exceptions), but we can also capture differences between languages (and between constructions within a language) in whether nominative case can be licensed on an object in dative and ergative subject constructions. This hybrid approach allows us to simplify the theory and make it more restrictive by eliminating all cross-linguistic differences in the structural cases that heads can license.

\section{Conclusion}

This chapter has shown that adding an OT-evaluation to MP can be done in a very 'minimal' way, simply by introducing the idea that the output of the computational system is filtered in an optimality-theoretic fashion by means of a language-specific ranking of otherwise universal constraints. The introduction of such an optimality-theoretic evaluator eliminates the need for many other devices that are currently used in MP to capture cross-linguistic differences such as language-specific filters of the type in (16) and parameter settings. Ranked violable constraints are superior to parameters set at 'on' or 'off' for a language as a whole, because parameters do not allow a requirement to hold in some situations, but not in others within the same language. Ranked violable constraints are always active and may affect the optimal output whenever they do not conflict with higher ranked constraints. This allows us to account for intricate patterns of data involving object shift and case that are beyond the reach of the traditional filters and parameters. We have also shown that ranked constraints allow us to further the goal of the minimalist program by enabling us to eliminate other devices such as EPP-features and language-specific case features on particular heads.

\section{References}

Archangeli, Diana. 1997. Optimality Theory. An introduction to linguistics in the 1990s. In Optimality theory: an overview, eds. Diana Archangeli and Terence Langendoen, 134-170. Malden/Oxford, Blackwell.

Belletti, Adriana. 1988. The Case of unaccusatives. Linguistic Inquiry 19:1-34.

Bittner, Maria. 1991. Case, Scope, and Binding. Dordrecht: Kluwer. 
Bittner, Maria, and Ken Hale. 1996. The Structural Determination of Case and Agreement. Linguistic Inquiry 27:1-68.

Blake, Barry J. 2001. Case. Cambridge: Cambridge University Press (2nd edition).

Blutner, Reinhard. 2000. Some aspects of optimality in natural language interpretation. Journal of Semantics 17:189-216.

Boeckx, Cedric, and Sandra Stjepanovic. 2001. Head-ing toward PF. Linguistic Inquiry 32:345-355.

Boersma, Paul. 1998. Functional phonology. Formalizing the interactions between articulatory and perceptual drives, IfOTT/University of Amsterdam: PhD.-thesis.

Bok-Bennema, Reineke. 1991. Case and agreement in Inuit. Dordrecht: Foris Publications.

Bresnan, Joan. 2000. Optimal Syntax. In Optimality Theory: phonology, syntax and acquisition, eds. Joost Dekkers, Frank Van der Leeuw and Jeroen Van de Weijer, 334-385. Oxford, Oxford University Press.

Broekhuis, Hans. 2000. Against feature strength: the case of Scandinavian object shift. Natural Language and Linguistic Theory 18:673-721.

Broekhuis, Hans. 2005. Extraction from subjects: some remarks on Chomsky's On Phases. In Organizing grammar. Linguistic studies in honor of Henk van Riemsdijk, eds. Hans Broekhuis, Norbert Corver, Riny Huybregts, Ursula Kleinhenz and Jan Koster. Berlin/New York, Mouton de Gruyter.

Broekhuis, Hans. 2008. Derivations and evaluations: object shift in the Germanic languages. Berlin/New York: Mouton de Gruyter.

Broekhuis, Hans, and Joost Dekkers. 2000. The minimalist program and optimality theory: derivations and evaluations. In Optimality Theory: phonology, syntax and acquisition, eds. Joost Dekkers, Frank van der Leeuw and Jeroen van de Weijer, 386-422. Oxford/New York, Oxford University Press.

Burzio, Luigi. 1986. Italian syntax: a government-binding approach. Dordrecht/Boston/Lancaster/Tokyo: Reidel.

Burzio, Luigi. 2000. Anatomy of a Generalization. In Arguments and Case: Explaining Burzio's Generalization, ed. Eric Reuland, 195-240. Amsterdam, John Benjamins.

Chomsky, Noam. 1986. Barriers. Cambridge, Mass.: MIT Press.

Chomsky, Noam. 1995. The minimalist program. Cambridge (Mass.): MIT Press.

Chomsky, Noam. 2000. Minimalist inquiries: the framework. In Step by step. Essays on minimalist syntax in honor of Howard Lasnik, eds. Roger Martin, David Michaels and Juan Uriagereka, 89-155. Cambridge (Mass.), MIT Press.

Chomsky, Noam. 2001. Derivation by phase. In Ken Hale. A life in Language, ed. Michael Kenstowicz, 1-52. Cambridge (Mass.), MIT Press.

Chomsky, Noam. 2004. Beyond explanatory adequacy. In Structures and beyond, ed. Adriana Belletti, 104-131. Oxford, Oxford University Press.

Chomsky, Noam. 2007. Approaching UG From Below. In Interfaces + Recursion $=$ Language?, eds. Uli Sauerland and Hans-Martin Gärtner, 1-29. Berlin/New York, Mouton de Gruyter.

Chomsky, Noam. 2008. On phases. In Foundational Issues in Linguistic Theory. Essays in Honor of Jean-Roger Vergnaud, eds. Robert Freidin, Carlos P. Otero and Maria Luisa Zubizarreta, 133-166. Cambridge (Mass.)/Oxford, MIT Press.

Chomsky, Noam, and Howard Lasnik. 1977. Filters and control. Linguistic Inquiry 8:425504.

Costa, João. 1998. Word order variation. A constraint-based approach, University of Leiden/LOT: PhD. thesis.

Dekkers, Joost. 1999. Derivations \& Evaluations. On the syntax of subjects and complementizers, University of Amsterdam/HIL: PhD. thesis. 
Den Dikken, Marcel. 2006. Relators and Linkers. The syntax of predication, predicate inversion, and copulas. Cambridge (Mass.)/London: MIT Press.

Den Dikken, Marcel. 2007. Phase Extension. Contours of a theory of the role of head movement in phrasal extraction. Theoretical Linguistics 33:1-41.

Dewey, Tonya Kim. 2006. The Origins and Development of Germanic V2, University of california, Berkeley: PhD. thesis.

Diesing, Molly. 1997. Yiddish VP order and the typology of object movement in Germanic. Natural Language and Linguistic Theory 17:369-427.

Fortson , Benjamin W. IV. 2004. Indo-European language and culture: An introduction. Oxford: Blackwell.

Godard, G. 1992. Extraction out of NP in French. Natural language and Linguistic Theory 10:233-277.

Grimshaw, Jane. 1997. Projection, heads and optimality. Linguistic Inquiry 28:373-422.

Groat, Erich, and John O'Neil. 1996. Spell-Out at the LF interface. In Minimal Ideas. Syntactic studies in the minimalist framework, eds. Werner Abraham, Samuel David Epstein and Höskuldur Thráinsson, 113-139. Amsterdam/Philadelphia, John Benjamins.

Hale, Ken. 1982. Some essential features of Warlpiri verbal clauses. In Papers in Warlpiri grammar: in memory of Lothar Jagst (Working Papers of SIL-ABB Series A Volume 6) ed. Stephen Swartz, 217-315. Darwin, Summer Institute of Linguistics.

Heck, Fabian, and Gereon Müller. 2000. Successive Cyclicity, Long-Distance Superiority, and Local Optimization. In WCCFL 19, eds. Roger Billerey and Brook Danielle Lillehaugen, 218-231. Somerville (Mass.) Cascadilla Press.

Holmberg, Anders. 1986. Word order and syntactic features in the Scandinavian languages and English, University of Stockholm, Department of General Linguistics: PhD. thesis.

Holmberg, Anders. 1999. Remarks on Holmberg's generalization. Studia Linguistica 53:1-39. Johnson, Kyle. 1991. Object positions. Natural language and Linguistic Theory 9:577-636.

Jónsson, Jóhannes G. 1996. Clausal architecture and Case in Icelandic, GLSA: University of Massachusetts: PhD. thesis.

Kayne, Richard S. 1994. The antisymmetry of syntax. Cambridge (Mass.): MIT Press.

Lasnik, Howard. 1999a. Minimalist analysis. Oxford: Blackwell.

Legate, Julie. 2006. Split absolutive. In Ergativity: Emerging Issues, eds. Alana Johns, Diane Massam and Juvenal Ndayiragije, 143-171. Dordrecht, Kluwer.

Legendre, G., Y. Miyata, and Paul Smolensky. 1990. Can connectionism contribute to syntax? Harmonic Grammar, with an Application. Proceedings of the 26th Meeting of the Chicago Linguistic Society.

Mahajan, Anoop. 1990. The A/A-bar distinction and movement theory, MIT: PhD. thesis.

Mahajan, Anoop. 1991. Clitic doubling, object agreement and specificity. NELS 21:263-277.

McCarthy, John. 2007. Hidden Generalizations: Phonological Opacity in Optimality Theory. London: Equinox Publications.

McCarthy, John. 2008. The serial interaction of stress and syncope. Natural Language and Linguistic Theory 26:499-546.

McCarthy, John, and Allen Prince. 1993. Prosodic morphology: constraint interaction and satisfaction. Ms. University of Massachusetts, Amherst/Rutgers University, http://roa.rutgers.edu/files/482-1201/482-1201-MCCARTHY-0-1.PDF.

Müller, Gereon. 1999. Optionality in Optimality-Theoretic Syntax. Glot Interntional 4:5:3-8.

Müller, Gereon. 2000. Shape conservation and remnant movement. In Proceedings of NELS 30, eds. A. Hirotani, N. Hall Coetzee and J.-Y. Kim, 525-539. Amherst (Mass.), GLSA. 
Müller, Gereon. 2001. Order preservation, parallel movement, and the emergence of the unmarked. In Optimality-theoretic syntax, eds. Géraldine Legendre, Jane Grimshaw and Sten Vikner, 113-142. Cambridge (Mass.)/London, MIT Press/MITWPL.

Pesetsky, David. 1997. Optimality theory and syntax: movement and pronunciation. In Optimality theory, eds. Diana Archangeli and Terence Langendoen. Malden/Oxford, Blackwell.

Pesetsky, David. 1998. Some optimality principles of sentence pronunciation. In $I s$ the best good enough?, eds. Pilar Barbosa, Danny Fox, Paul Hagstrom, Martha McGinnis and David Pesetsky, 337-383. Cambridge (Mass.)/London, MIT Press/MITWPL.

Pollock, Jean-Yves. 1989. Verb movement, Universal Grammar and the structure of IP. Linguistic Inquiry 20:365-424.

Prince, Alan, and Paul Smolensky. 1993. Optimality: Constraint Interaction in Generative Grammar. Rutgers University Center for Cognitive Science (published as 2004).

Prince, Alan, and Paul Smolensky. 2004. Optimality Theory: Constraint Interaction in Generative Grammar. Malden (Mass.)/Oxford: Blackwell.

Prince, Alan, and Bruce Tesar. 2010. OT Workplace 0.9.9.8beta. http://ruccs.rutgers.edu/ prince/papers/otwpl_0.9.9.8beta.xls.

Reuland, Eric (ed.). 2000. Argument and Case: Explaining Burzio's Generalization. Amsterdam: John Benjamins.

Rizzi, Luigi. 1990. Relativized Minimality. Cambridge (Mass.)/London: MIT Press.

Rizzi, Luigi. 2001. Relativized minimality effects. In The Handbook of Contemporary Syntactic Theory, eds. Mark Baltin and Chris Collins. Oxford, Blackwell.

Schütze, Carson Theodore Robert. 1997. INFL in child and adult language: agreement, case and licensing, MIT: PhD. thesis.

Sells, Peter. 2001. Structure Alignment and optimality in Swedish. Stanford: CSLI Publications.

Simpson, Jane. 1991. Warlpiri Morpho-Syntax: A Lexicalist Approach. Dordrecht: Kluwer.

Taraldsen, Knut Tarald. 1995. On agreement and nominative subjects in Icelandic. In Studies in comparative Germanic syntax, eds. Hubert Haider, Susan Olsen and Sten Vikner. Dordrecht/Boston/London, Kluwer Academic Publishers.

Thráinsson, Höskuldur, Hjalmar P. Petersen, Jógvan í Lon Jacobsen, and Zakaris Svabo Hansen. 2004. Faroese: An Overview and Reference Grammar. Tórshavn: Føroya Fróðskaparfelag.

Ussery, Cherlon 2009. Optionality and Variability: Syntactic Licensing Meets Morphological Spell-Out, University of Amherst: PhD. thesis.

Vikner, Sten. 1994. Scandinavian object shift and West Germanic scrambling. In Studies on Scrambling. Movement and non-movement approaches to free word-Order phenomena, eds. Norbert Corver and Henk van Riemsdijk, 487-517. Berlin/New York, Mouton de Gruyter.

Vikner, Sten. 2006. Object Shift. In The Blackwell companion to Syntax, eds. Martin Everaert and Henk van Riemsdijk, 392-436. Malden (Mass.)/Oxford, Blackwell Publishing.

Vogel, Ralf. 2006a. The simple generator. In Optimality Theory and Minimalism: A Possible Convergence? Linguistics in Potsdam 25, eds. Hans Broekhuis and Ralf Vogel. University of Potsdam: http://www.ling.uni-potsdam.de/lip.

Vogel, Ralf. 2006b. Weak Function Word Shift. Linguistics 44:1059-1093.

Watanabe, Akira. 1993. Agr-based Case Theory and its Interaction with the A-bar System, MIT: $\mathrm{PhD}$. thesis.

Williams, Edwin. 2003. Representation theory. Cambridge (Mass.)/London: MIT Press.

Woolford, Ellen. 2001. Case patterns. In Optimality Theoretic Syntax, eds. Géraldine Legendre, Sten Vikner and Jane Grimshaw. Cambridge (Mass.), MIT. 
Woolford, Ellen. 2003a. Burzio's Generalization, Markedness, and constraints on nominative objects. In New Perspectives on Case Theory, eds. Ellen Brandner and H. Zinsmeister, 301-329. Stanford, CSLI Publications.

Woolford, Ellen. 2003b. Nominative objects and Case locality. In Formal Approaches to Slavic Linguistics 11, ed. W. Browne et al. Ann Arbor, Michigan Slavic Publications.

Woolford, Ellen. 2006. Lexical Case, inherent Case, and argument structure. Linguistic Inquiry 37:111-130.

Woolford, Ellen. 2007. Case locality: Pure domains and object shift. Lingua 117:1591-1616.

Yip, Moira, Joan Maling, and Ray Jackendoff. 1987. Case in tiers. Language 217-250.

Zwart, Jan Wouter. 2001. Syntactic and phonological verb movement. Syntax 4:34-62. 